Article

\title{
Estimating Leaf Area Index with a New Vegetation Index Considering the Influence of Rice Panicles
}

\author{
Jiaoyang He $\mathrm{He}^{1,2,3,4}$, Ni Zhang $1,2,3,4$, Xi Su ${ }^{1,2,3,4}$, Jingshan Lu ${ }^{1,2,3,4}$, Xia Yao ${ }^{1,2,3,4}$, \\ Tao Cheng $1,2,3,4\left(\mathbb{D}\right.$, Yan Zhu ${ }^{1,2,3,4} \mathbb{D}^{\text {, Weixing Cao }}{ }^{1,2,3,4}$ and Yongchao Tian $1,2,3,4, *$ \\ 1 National Engineering and Technology Center for Information Agriculture, Nanjing Agricultural University, \\ Nanjing 210095, China \\ 2 Key Laboratory for Crop System Analysis and Decision Making, Ministry of Agriculture and Rural Affairs, \\ Nanjing Agricultural University, Nanjing 210095, China \\ 3 Jiangsu Key Laboratory for Information Agriculture, Nanjing Agricultural University, Nanjing 210095, China \\ 4 Jiangsu Collaborative Innovation Center for Modern Crop Production, Nanjing Agricultural University, \\ Nanjing 210095, China \\ * Correspondence: yctian@njau.edu.cn; Tel.: +86-25-84399050; Fax: +86-25-84396672
}

Received: 12 June 2019; Accepted: 30 July 2019; Published: 1 August 2019

\begin{abstract}
The emergence of rice panicle substantially changes the spectral reflectance of rice canopy and, as a result, decreases the accuracy of leaf area index (LAI) that was derived from vegetation indices (VIs). From a four-year field experiment with using rice varieties, nitrogen $(\mathrm{N})$ rates, and planting densities, the spectral reflectance characteristics of panicles and the changes in canopy reflectance after panicle removal were investigated. A rice "panicle line"-graphical relationship between red-edge and near-infrared bands was constructed by using the near-infrared and red-edge spectral reflectance of rice panicles. Subsequently, a panicle-adjusted renormalized difference vegetation index (PRDVI) that was based on the "panicle line" and the renormalized difference vegetation index (RDVI) was developed to reduce the effects of rice panicles and background. The results showed that the effects of rice panicles on canopy reflectance were concentrated in the visible region and the near-infrared region. The red band $(670 \mathrm{~nm})$ was the most affected by panicles, while the red-edge bands $(720-740 \mathrm{~nm})$ were less affected. In addition, a combination of near-infrared and red-edge bands was for the one that best predicted LAI, and the difference vegetation index (DI) $(976,733)$ performed the best, although it had relatively low estimation accuracy $\left(R^{2}=0.60, R M S E=1.41 \mathrm{~m}^{2} / \mathrm{m}^{2}\right)$. From these findings, correcting the near-infrared band in the RDVI by the panicle adjustment factor ( $\theta)$ developed the PRDVI, which was obtained while using the "panicle line", and the less-affected red-edge band replaced the red band. Verification data from an unmanned aerial vehicle (UAV) showed that the PRDVI could minimize the panicle and background influence and was more sensitive to LAI $\left(\mathrm{R}^{2}=0.77\right.$; RMSE $\left.=1.01 \mathrm{~m}^{2} / \mathrm{m}^{2}\right)$ than other VIs during the post-heading stage. Moreover, of all the assessed VIs, the PRDVI yielded the highest R2 (0.71) over the entire growth period, with an RMSE of $1.31\left(\mathrm{~m}^{2} / \mathrm{m}^{2}\right)$. These results suggest that the PRDVI is an efficient and suitable LAI estimation index.
\end{abstract}

Keywords: panicle adjustment factor; panicle-adjusted renormalized difference vegetation index vegetation index; leaf area index

\section{Introduction}

The leaf area index (LAI) is a major biophysical parameter that is used to determine the vegetation canopy structure and population characteristics [1], and it is a key biophysical variable in vegetation photosynthesis, transpiration, respiration, and the carbon cycle [2,3]. Similarly, the LAI could 
quantitatively describe leaf area changes, which reflects the growth status of vegetation at the community level and shifts in net primary productivity [4-6]. Therefore, it is critical to study and develop methods that can rapidly and accurately determine the LAI.

A vegetation index (VI) is a spectral transformation of two or more bands to identify the contribution of vegetation properties. It is widely used to estimate the physiological and biochemical indicators, such as the LAI [7], aboveground biomass (AGB) [8], and leaf nitrogen content (LNC) [9]. Since the 1980s, numerous investigations have employed VIs to study the LAI. VIs can be divided into two major categories, according to the formula types and application requirements. One group consists of simple mathematical combinations of bands, such as spectral differences or ratios. Jordan [10] first proposed the difference vegetation index (DI) and the ratio vegetation index (SR) for the rapid estimation of LAI. Guo et al. [11] developed DI $(800,750)$ to monitor the LAI of rice. Li and Wang [12] reported that DI $(920,1080)$ could minimize the influence of canopy vertical heterogeneity and accurately estimate the LAI of beech. Due to the nonlinear relationship between the normalized difference vegetation index (NDVI) and LAI for dense vegetation canopy [13], Roujean and Breon [14] and Chen [15] proposed the renormalized difference vegetation index (RDVI) and the modified simple ratio (MSR) to minimize the saturation effect.

Another type of VI was developed to eliminate the influence of endmembers (e.g., soil background, atmosphere) at the subpixel scale. The most representative VI in this group is the soil adjusted vegetation index (SAVI) that was proposed by Huete [16]. Further development of the SAVI concept resulted in the optimized SAVI (OSAVI) [17]. Kaufman and Tanre [18] proposed the soil and atmospheric resistance vegetation index (SARVI) to eliminate the influence of background and atmospheric aerosols. Peddle et al. [19] developed a novel sunlit canopy adjusted vegetation index (SCAVI) to improve the accuracy of estimations of physiological and biochemical parameters (e.g., LAI) that are influenced by background and varying lighting conditions while using the principle of spectral mixture analysis at the subpixel scale. Haboudane et al. [20] proposed the modified triangular vegetation index (MTVI2) on the basis of the triangular vegetation index (TVI), and the modified index eliminated the effects of chlorophyll, soil, and atmosphere when estimating LAI. Previous studies have shown that the enhanced vegetation index (EVI) is less affected by soil background noise and sensitive to LAI values that were lower than 2 or $3 \mathrm{~m}^{2} / \mathrm{m}^{2}$ [21]. When compared with a single vegetation index, simple combinations of VIs (e.g., OSAVI $\times$ EVI2, TCARI/OSAVI, PPR/NDVI) produce higher accuracy estimates of physiological and biochemical parameters, such as LAI [22-24].

In gramineous crops, such as rice and wheat, the influence of soil background is prominent during early growth stages, and it decreases as vegetation cover (VC) increases. Numerous studies have shown that the appearance of panicles can not only change the light distribution in a crop canopy, but also considerably affect canopy spectral reflectance [25-28]. Inoue et al. [29] and Asilo et al. [30] also reported that panicles influence the relationship between X-band and LAI in rice. Therefore, the influence of panicles on canopy structure is a key factor that affects LAI estimation accuracy during the late growth stages of crops. This is problematic due to the accurate estimation of crop yields during late growth stages often relies on the accurate estimation of LAI [31]. Although some VIs (e.g., SAVI and OSAVI) account for the influence of soil background noise and are well correlated with LAI during early growth stages, the modification of soil background noise cannot eliminate the influence of changes in canopy structure that are caused by panicles after the heading stage. Despite its importance, few studies have examined the effect of panicles on canopy spectra.

Our specific aims are to (1) study the effects of rice panicles on canopy reflectance; (2) evaluate the influence of rice panicles on the prediction accuracy and stability of VIs that are used to estimate LAI; and, (3) develop a new panicle- and soil-adjusted vegetation index to improve the estimation accuracy of rice LAI in the post-heading stage. 


\section{Materials and Methods}

\subsection{Study Area and Experimental Details}

Five rice field experiments were conducted in the experimental station of the National Engineering and Technology Center for Information Agriculture in Rugao City, Jiangsu Province, China $\left(120^{\circ} 45^{\prime} \mathrm{E}\right.$, $\left.32^{\circ} 16^{\prime} \mathrm{N}\right)$. The experiments involved different nitrogen $(\mathrm{N})$ rates, planting densities, and rice cultivars in different years (Table 1). The experimental details are described below.

Table 1. Detailed information on the field treatments adopted in the present study.

\begin{tabular}{|c|c|c|c|c|}
\hline & Cultivar & $\begin{array}{c}\text { Nitrogen } \\
\text { Fertilization Rate } \\
\left(\mathbf{k g} \cdot \mathrm{ha}^{-1}\right)\end{array}$ & $\begin{array}{l}\text { Plant Density } \\
\text { (Plants } \mathrm{m}^{-2} \text { ) }\end{array}$ & $\begin{array}{c}\text { Sampling and Spectral } \\
\text { Measurement Data } \\
\left(\text { DAT }^{\mathrm{a}}\right)\end{array}$ \\
\hline $\begin{array}{l}\text { Exp.1 } \\
(2013)\end{array}$ & $\begin{array}{l}\text { Wuxiangjing } 14 \\
\text { (WXJ14, V1) } \\
\text { Shanyou 63 } \\
\text { (SY63, V2) }\end{array}$ & $\begin{array}{l}150(\mathrm{~N} 2) \\
300(\mathrm{~N} 3)\end{array}$ & $\begin{array}{l}22.22 \text { (D2) } \\
13.33 \text { (D4) }\end{array}$ & $\begin{array}{c}28,40,58 \\
69,83,91,109\end{array}$ \\
\hline $\begin{array}{l}\text { Exp.2 } \\
\text { (2014) }\end{array}$ & $\begin{array}{l}\text { Wuyunjing } 24 \\
\text { (WYJ24, V3) } \\
\text { Eryou 728 } \\
\text { (EY728, V4) }\end{array}$ & $\begin{array}{l}150(\mathrm{~N} 2) \\
300(\mathrm{~N} 3)\end{array}$ & $\begin{array}{l}33.33(\mathrm{D} 1) \\
22.22(\mathrm{D} 2) \\
16.66(\mathrm{D} 3)\end{array}$ & $\begin{array}{c}28,40,50,68 \\
79,86,102,119\end{array}$ \\
\hline $\begin{array}{l}\text { Exp.3 } \\
\text { (2015) }\end{array}$ & $\begin{array}{l}\text { Wuyunjing } 24 \\
\text { (WYJ24, V3) } \\
\text { Eryou 728 } \\
\text { (EY728, V4) }\end{array}$ & $\begin{array}{l}100(\mathrm{~N} 1) \\
300(\mathrm{~N} 3)\end{array}$ & $\begin{array}{l}22.22(\mathrm{D} 2) \\
16.66(\mathrm{D} 3) \\
13.33(\mathrm{D} 4)\end{array}$ & $\begin{array}{c}37,43,50,58 \\
71,86,95,96^{\mathrm{b}} \\
101,102^{\mathrm{b}}, 117,118^{\mathrm{b}}\end{array}$ \\
\hline $\begin{array}{l}\text { Exp.4 } \\
\text { (2016) }\end{array}$ & $\begin{array}{l}\text { Wuyunjing } 24 \\
\text { (WYJ24, V3) } \\
\text { Eryou 728 } \\
\text { (EY728, V4) }\end{array}$ & $\begin{array}{l}100(\mathrm{~N} 1) \\
300(\mathrm{~N} 3)\end{array}$ & $\begin{array}{l}22.22(\mathrm{D} 2) \\
16.66(\mathrm{D} 3) \\
13.33(\mathrm{D} 4)\end{array}$ & $\begin{array}{c}24,41,50,59 \\
73,87,89^{\mathrm{b}}, 96 \\
98^{\mathrm{b}}, 113,114^{\mathrm{b}}\end{array}$ \\
\hline $\begin{array}{l}\text { Exp.5 } \\
(2015)\end{array}$ & $\begin{array}{l}\text { Wuyunjing } 24 \\
\text { (WYJ24, V3) } \\
\text { Y Liangyou } 1 \\
\text { (YL1, V5) }\end{array}$ & $\begin{array}{c}0(\mathrm{~N} 0) \\
100(\mathrm{~N} 1) \\
300(\mathrm{~N} 3)\end{array}$ & $\begin{array}{l}22.22(\mathrm{D} 2) \\
13.33(\mathrm{D} 4)\end{array}$ & 82,99 \\
\hline
\end{tabular}

Experiment 1 (Exp.1) was conducted from May to November 2013. One japonica rice cultivar, Wuxianging14 (V1, with erect leaves and panicles), and one indica rice cultivar, Shanyou63 (V2, with spread leaves and panicles), were seeded on May 15 and then transplanted into the paddy field on June 15. Two $\mathrm{N}$ rates $\left(\mathrm{N} 1=100 \mathrm{~kg} \mathrm{~N} \mathrm{ha}^{-1}\right.$ and N3 $=300 \mathrm{~kg} \mathrm{~N}$ ha $\left.^{-1}\right)$ were applied with two planting densities $\left(\mathrm{D} 2=22.22\right.$ plants $\mathrm{m}^{-2}$ and $\mathrm{D} 4=13.33$ plants $\left.\mathrm{m}^{-2}\right)$.

Experiment 2 (Exp.2) was conducted from May to November 2014. One japonica rice cultivar, Wuyunjing24 (V3, with erect leaves and panicles) and one indica rice cultivar, Eryou728 (V4, with spread leaves and panicles), were seeded on May 15 and then transplanted into the paddy field on June 15. Two $\mathrm{N}$ rates $\left(\mathrm{N} 2=150 \mathrm{~kg} \mathrm{~N} \mathrm{ha}^{-1}\right.$ and N3 $\left.=300 \mathrm{~kg} \mathrm{~N} \mathrm{ha}^{-1}\right)$ were applied with three planting densities $\left(\mathrm{D} 1=33.33\right.$ plants $\mathrm{m}^{-2}, \mathrm{D} 2=22.22$ plants $\mathrm{m}^{-2}$, and $\mathrm{D} 3=16.66$ plants $\mathrm{m}^{-2}$ ).

Experiments 3 (Exp.3) and 4 (Exp.4) were conducted from May to November in 2015 and 2016, respectively. Two $\mathrm{N}$ rates $\left(\mathrm{N} 1=100 \mathrm{~kg} \mathrm{~N} \mathrm{ha}^{-1}\right.$ and $\left.\mathrm{N} 3=300 \mathrm{~kg} \mathrm{~N} \mathrm{ha}^{-1}\right)$ were applied with three planting densities $\left(\mathrm{D} 2=22.22\right.$ plants $\mathrm{m}^{-2}, \mathrm{D} 3=16.66$ plants $\mathrm{m}^{-2}$, and $\mathrm{D} 4=13.33$ plants $\left.\mathrm{m}^{-2}\right)$. The rice cultivars and the dates of seeding and transplanting were the same as those in Exp.2.

Experiment 5 (Exp.5) was conducted from May to November 2015. One japonica rice cultivar, Wuyunjing24 (V3, with erect leaves and panicles), and one indica rice cultivar, Y Liangyou 1 (V5, with spread leaves and panicles), were seeded on May 15 and transplanted into the paddy field on June 15. Three $\mathrm{N}$ rates $\left(\mathrm{N} 0=0 \mathrm{~kg} \mathrm{~N} \mathrm{ha}^{-1}, \mathrm{~N} 1=100 \mathrm{~kg} \mathrm{~N} \mathrm{ha}^{-1}\right.$, and N3 $=300 \mathrm{~kg} \mathrm{~N} \mathrm{ha}^{-1}$ ) were applied with two planting densities $\left(\mathrm{D} 2=22.22\right.$ plants $\mathrm{m}^{-2}$ and $\mathrm{D} 4=13.33$ plants $\left.\mathrm{m}^{-2}\right)$.

Each treatment in the five experiments had three replicates. The plot area was $30 \mathrm{~m}^{2}$, with the dimensions $6 \times 5 \mathrm{~m}$. The $\mathrm{N}$ fertilizers were applied, as follows: $40 \%$ as basal fertilizer before 
transplanting, 20\% at tillering stage, 20\% at the jointing stage, and $20 \%$ at the booting stage. The initial heading dates of experiments 1 to 5 were 77, 74, 76, 75, and 76 days after transplanting (DAT), respectively.

\subsection{Spectral Measurements}

Canopy spectral reflectance was measured with the FieldSpec4 Standard-Res (Analytical Spectral Device, Boulder, CO, USA). The spectral range of this instrument is $350-2500 \mathrm{~nm}$, and the view angle is $25^{\circ}$. All of the spectral measurements were performed $1 \mathrm{~m}$ above the rice canopy between 10:00 and 14:00 in cloud-free conditions. Five fixed points (where the tiller number is the same or similar to the average tiller number of the plot) were selected in each plot for spectral measurements throughout the growing period, and the spectral reflectance at each point was recorded three times. The averaged spectrum was calculated and regarded as the value for that plot by using the software ViewSpecPro (Analytical Spectral Device, Boulder, CO, USA). The reflectance of a white reference panel was determined before each measurement. This white reference panel reflects a high $99 \%$ of the radiation in the measured wavelengths, and that it is what is used as a reference to calculate the reflectance of the rice canopy.

In addition to conventional spectral measurements, the spectral reflectance of the rice canopy before and after the removal of panicles were measured during the post-heading stages in Exp.3 (96, 102, 118 DAT) and Exp.4 (89, 98, 114 DAT). First, the spectral reflectance of the original canopy (Figure 1a) was measured ( $R_{\text {original canopy }}$ ), all of the panicles in the instrument field of view were cut off, and then the spectral reflectance of the remaining rice canopy was measured again (Figure $1 b)$ ( $R_{\text {canopy without panicles }}$ ). Finally, the spectral reflectance of the panicles $\left(R_{\text {panicles }}\right)$ was measured (the sensor was $0.1 \mathrm{~m}$ above the panicles), as shown in Figure 2. Figure 3 shows $R_{\text {original canopy, }} R_{\text {canopy without panicles, }} R_{\text {panicles, }}$, the relative variation rate $\left(R_{V}, \%\right)$, and the difference $(D)$ between $R_{\text {original canopy }}$ and $R_{\text {canopy without panicles }}$.

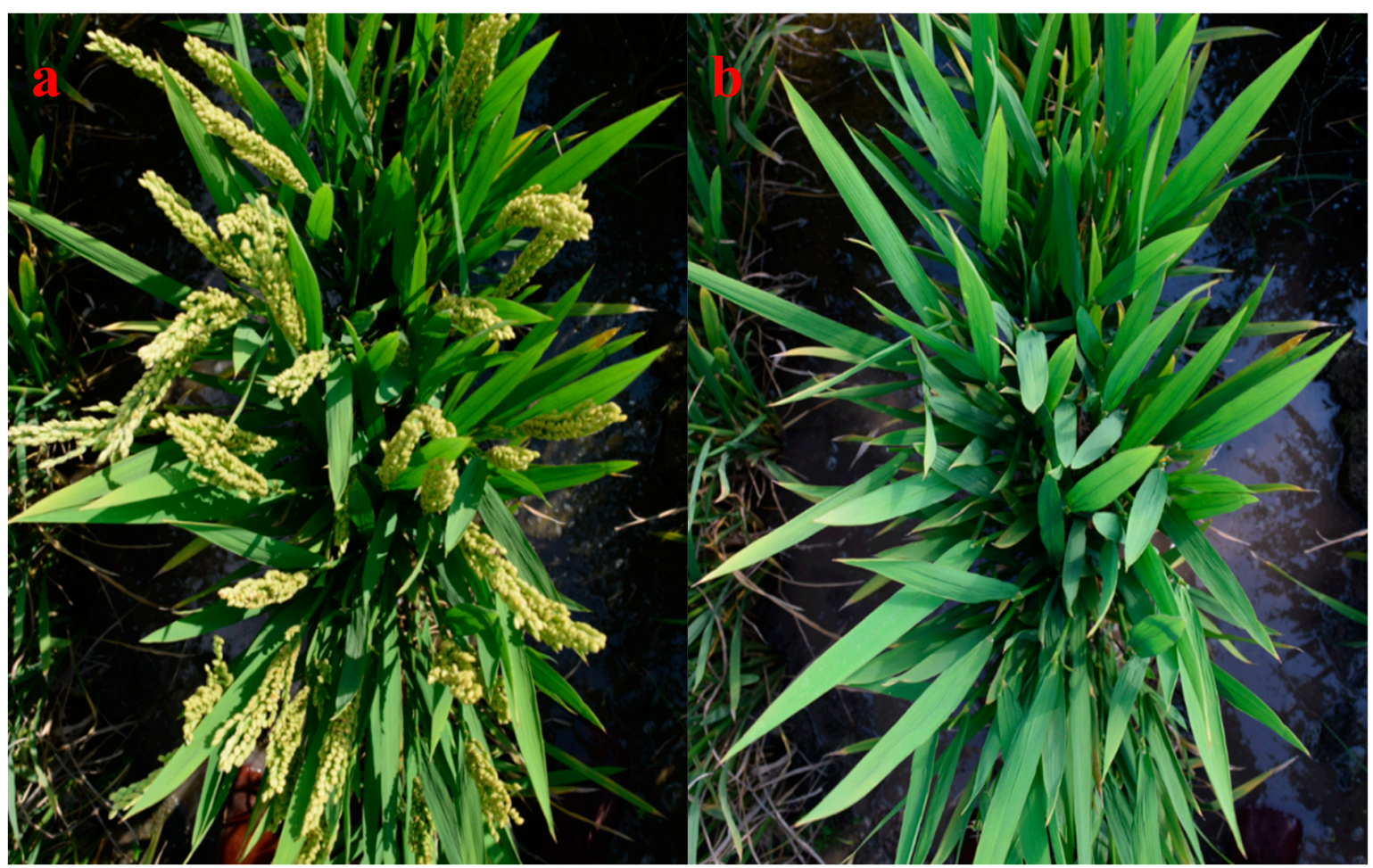

Figure 1. Views of rice canopy before and after panicle removal. (a) is the original rice canopy, and (b) is the rice canopy without panicles. 


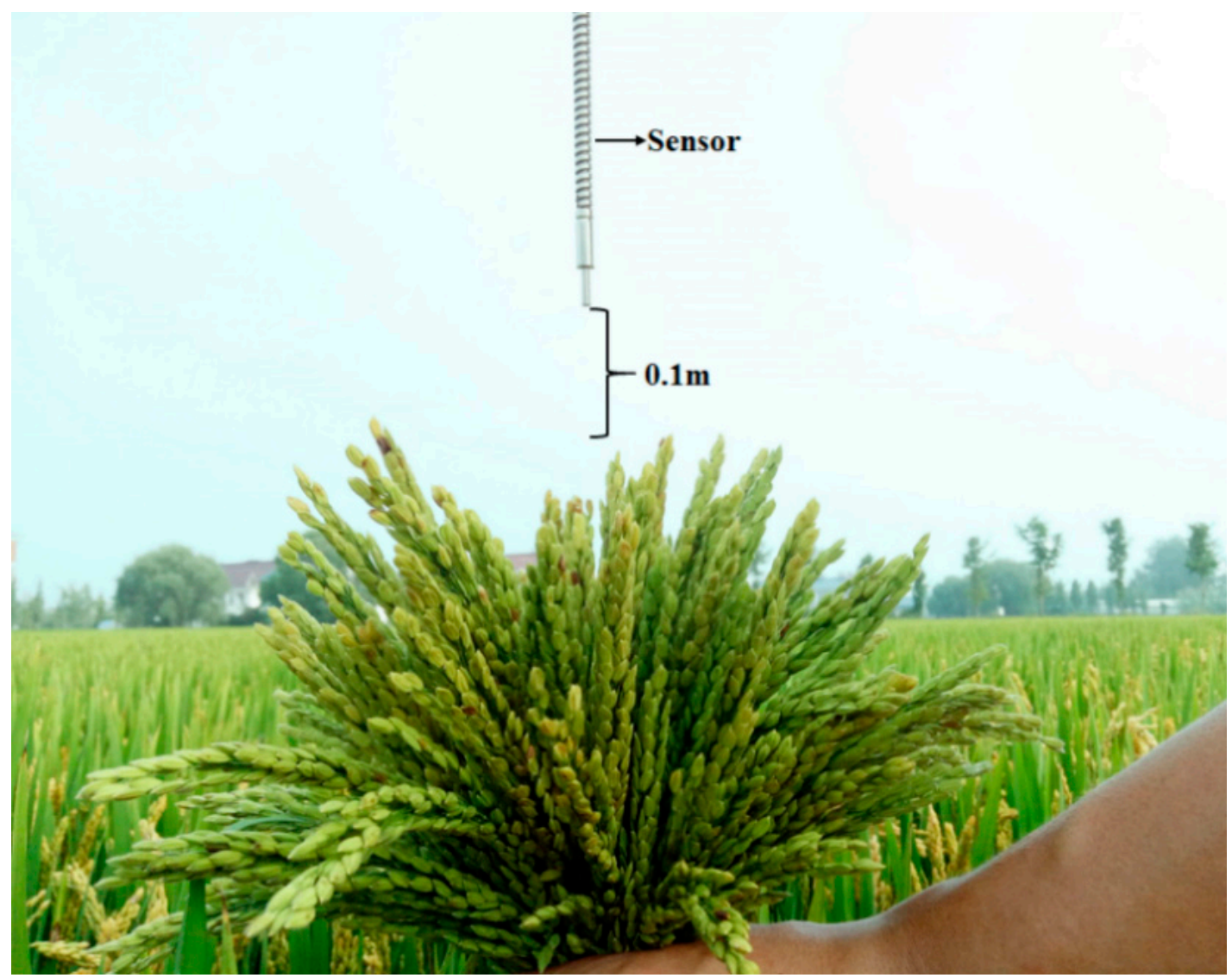

Figure 2. Measurement of panicle reflectance.
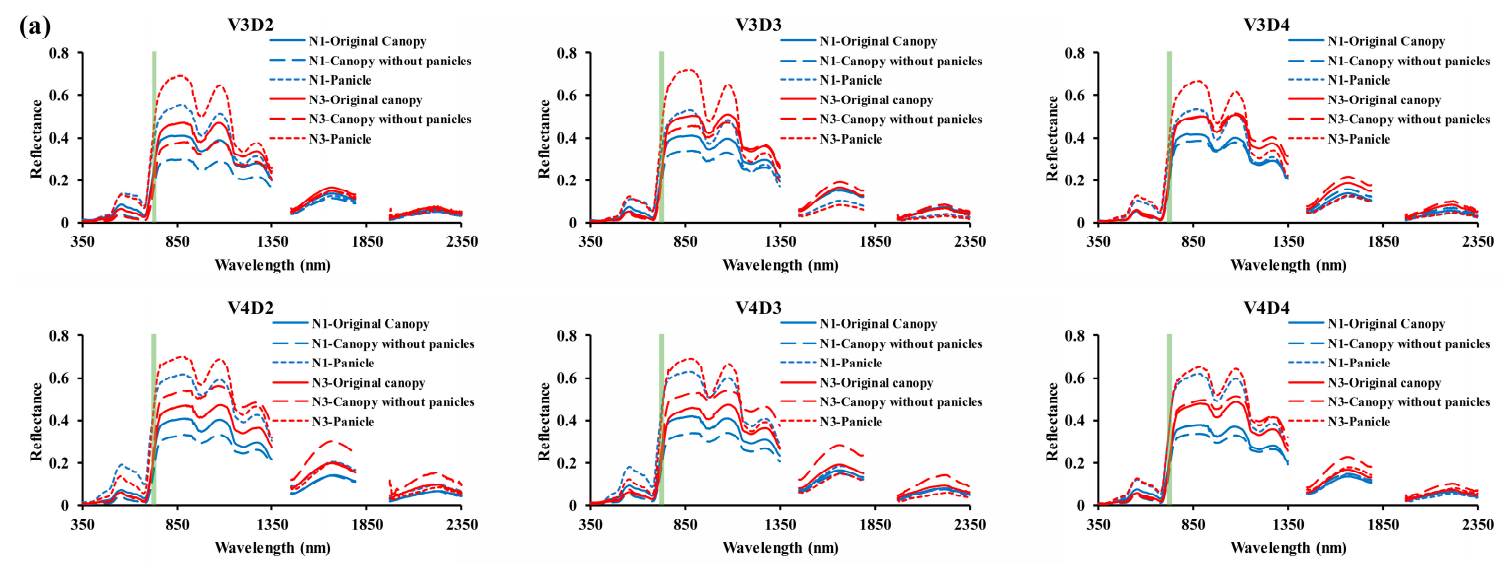

Figure 3. Cont. 

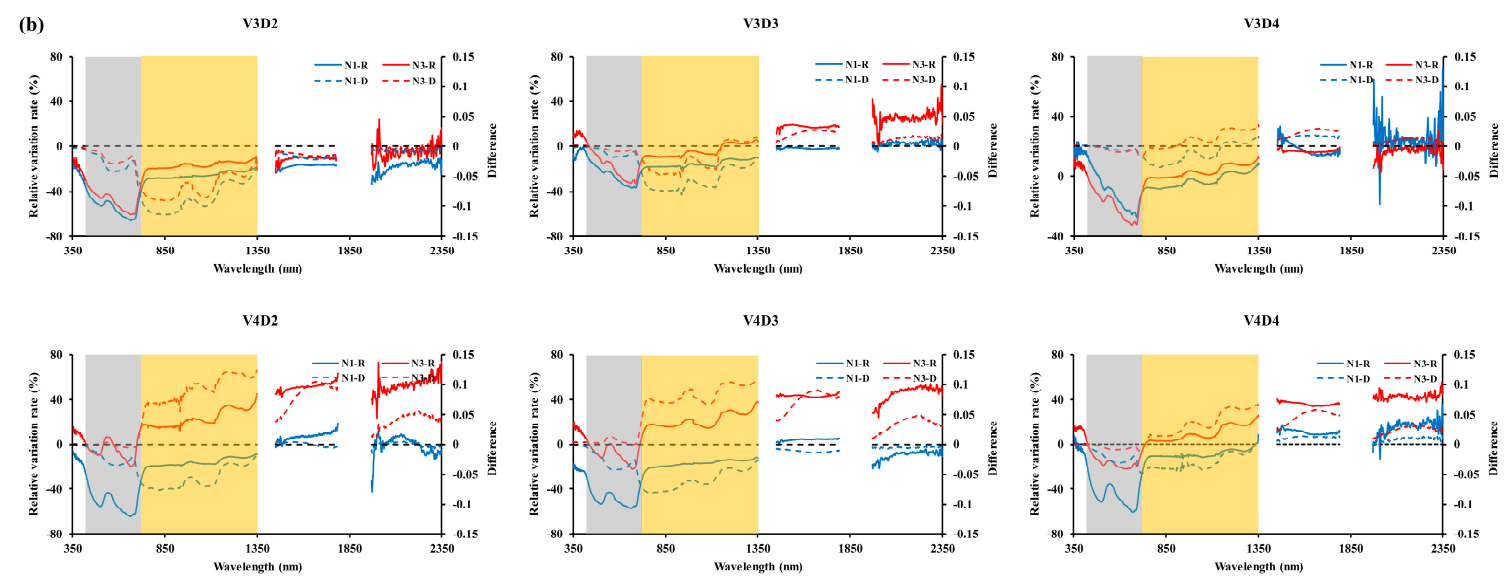

Figure 3. Influence of panicles on the reflectance of rice canopy. (a) is the variations in the spectral signature of rice canopies before $\left(R_{\text {original canopy }}\right)$ and after $\left(R_{\text {canopy without panicles }}\right)$ the removal of panicles, and (b) is the relative variation rates (\%) and the differences between $R_{\text {original canopy }}$ and $\mathrm{R}_{\text {canopy without panicles }}$ for different varieties (V3 = WYJ24, V4 = EY728) and transplanting densities $\left(\mathrm{D} 2=22.22\right.$ plants $\mathrm{m}^{-2}, \mathrm{D} 3=16.66$ plants $\mathrm{m}^{-2}, \mathrm{D} 4=13.33$ plants $\left.\mathrm{m}^{-2}\right)$. The sampling date was 96 days after transplanting (2015). Significant noise in the reflectance (caused by the effects of atmospheric moisture) was removed in the wavelength ranges 1351-1380, 1781-1970, and 2351-2500 nm. The color-shaded areas in (a) and (b) represent 720-740 (green), 450-730 (gray), and 730-1350 nm (yellow).

\subsection{UAV, Sensor, Image Acquisition and Processing}

The unmanned aerial vehicle (UAV) that was used in this study is a multi-rotor MK-Oktokopter manufactured by HiSystems GmbH. The maximum payload capacity is $2.5 \mathrm{~kg}$, and the maximum flight range is $1000 \mathrm{~m}$. The flight duration varies between 8 and $25 \mathrm{~min}$., depending on the battery and payload. A multispectral camera (Mini-MCA6; Tetracam, Inc., Chatsworth, CA, USA) was mounted on the UAV to acquire multispectral images. The band that was selected for this study comprises the center wavelengths of 490, 550, 680, 720, and $800 \mathrm{~nm}$.

The UAV campaign was conducted in clear-sky and low-wind-speed conditions between 10:00 and 14:00 local time. The MK-Tool autopilot was used to set the flight waypoints, and multispectral images were acquired at an altitude of $100 \mathrm{~m}$. The camera settings were adjusted according to the lighting conditions and set to a fixed exposure for each flight. The images were continuously acquired during the flight at $0.5 \mathrm{~Hz}$ and saved to memory cards. Note that the UAV only obtained images of 36 plots in Exp.5.

The processing workflow for the multispectral images includes noise correction, vignetting correction, lens distortion correction, band-to-band registration, band stacking, and radiometric calibration. All processing was performed while using the IDL script within the ENVI software package (EXELIS; Boulder, CO, USA). One hundred dark offset sample images were generated for each of the Mini-MCA channels at multiple exposure levels. The per-pixel average was calculated for each combination of sensor and exposure levels and stored as a noise correction file. Lens vignetting correction was based on spatially dependent correction factors. The correction factors for each sensor at multiple exposure levels were generated from the average of 100 flat field sample images with the uniform source system (CSTM-USS-1200C; Labsphere, Inc., New England, USA). A Brown-Conrady distortion model was adopted for lens distortion. Since the Mini-MCA6 has a significant band mis-registration effect, GCPs were used for band-to-band registration. For radiometric calibration, seven calibration targets $(1.2 \mathrm{~m} \times 1.2 \mathrm{~m})$ with nominal reflectance of $3 \%, 6 \%, 12 \%, 22 \%, 48 \%, 64 \%$, and $80 \%$ were placed within the UAV flight path and then captured in the mini-MCA imagery. The target's actual digital number (DN) values were extracted from the airborne image and the reflectance measured with a FieldSpec4 Standard-Res Spectroradiometer (Analytical Spectral Devices; Boulder, CO USA). The DNs in the raw images were then transformed into the ground measured reflectance data by 
applying an empirical linear correction method. Zhou et al. provided more detailed information on the UAV and the image processing [32].

\subsection{Determination of LAI}

After each canopy spectral reflectance measurement, three plants from each plot were randomly selected to determine leaf area. The green leaves were separated from the stems, and leaf area was measured using a leaf area meter (LI-3100C, LI-COR Inc., NE, USA), and then LAI was calculated in each plot from the planting densities. The spatial and temporal variation in rice LAI (Figure 4) showed that LAI increased and then decreased during the entire growth stage, and it increased with increased planting densities and $\mathrm{N}$ rates. The maximum LAI of japonica rice $(\mathrm{V} 1, \mathrm{~V} 3)$ was less than that of indica rice $(\mathrm{V} 2, \mathrm{~V} 4)$.
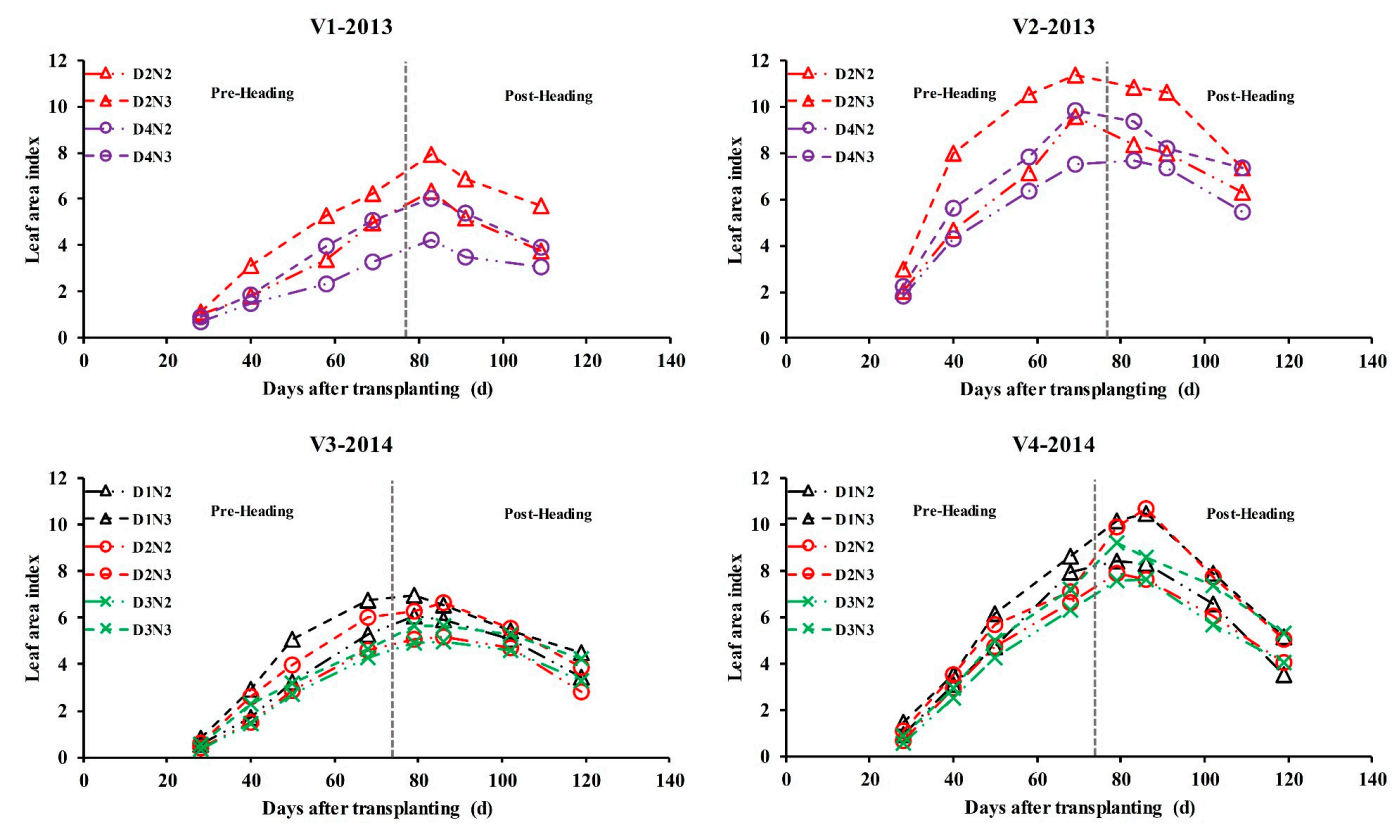

V3-2015
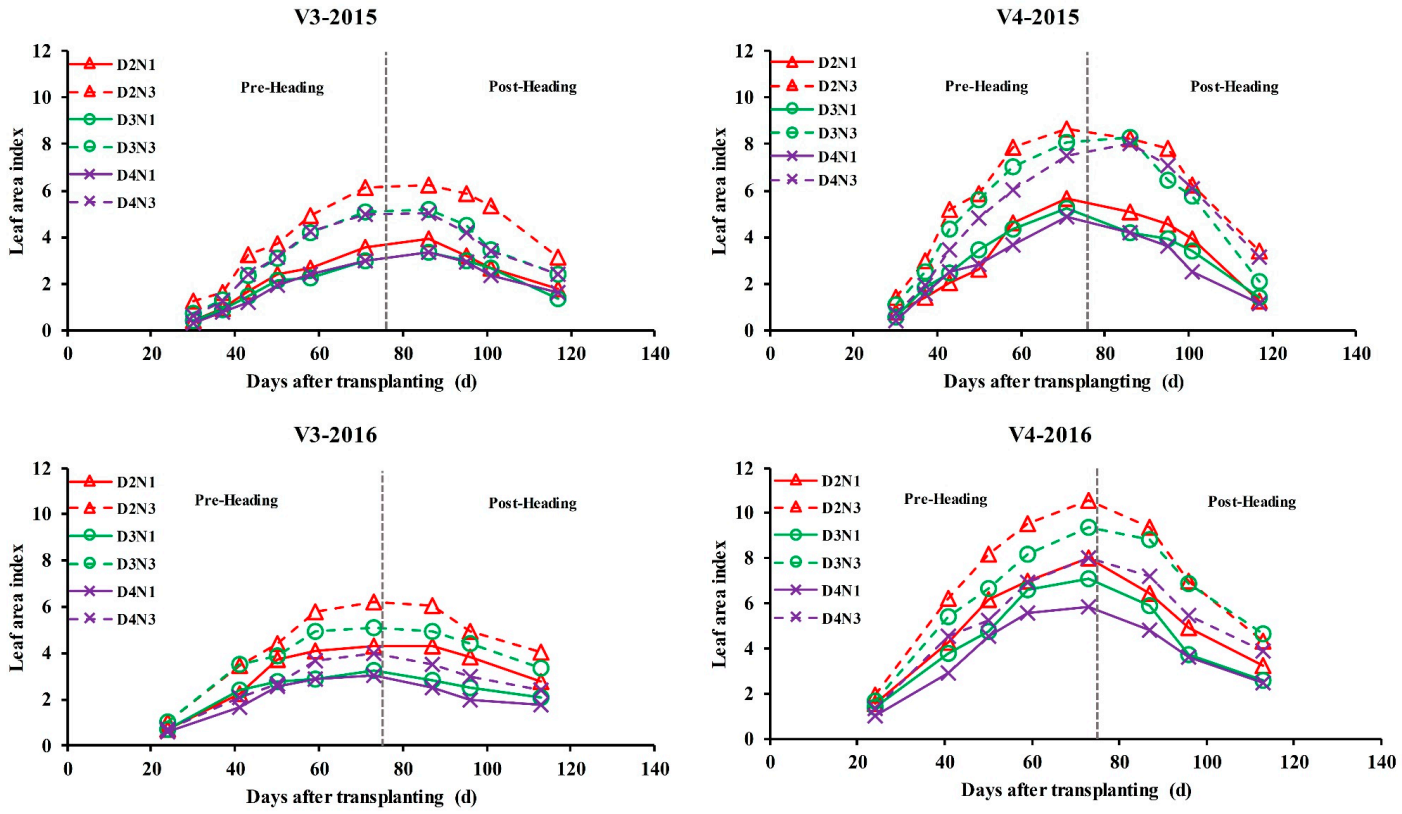

Figure 4. Variation in leaf area index (LAI) during the entire growth period of rice. Vertical dotted lines in the graph represent the initial heading period. The initial heading dates in 2013, 2014, 2015, and 2016 were $77,74,76$, and 75 days after transplanting, respectively. 


\subsection{Development of the Panicle-Adjusted Renormalized Difference Vegetation Index}

\subsubsection{Selection of Vegetation Index Form}

As a row crop, rice has a high planting density and complex background conditions, especially during its later growth stage (Figure 5). Therefore, a vegetation index that minimizes the effects of background and canopy structure is a prerequisite for the accurate estimation of LAI. Some of the VIs (such as NDVI) that are easily saturated under high LAI conditions are not suitable for estimating LAI during the late growth stage of rice [33]. Although the DI is not easily saturated under high LAI conditions, it is markedly affected by the spectral and directional canopy properties [14]. The RDVI, which combines the advantages of the DI and NDVI, is suitable for estimating LAI under complex background and high LAI conditions [14,20].

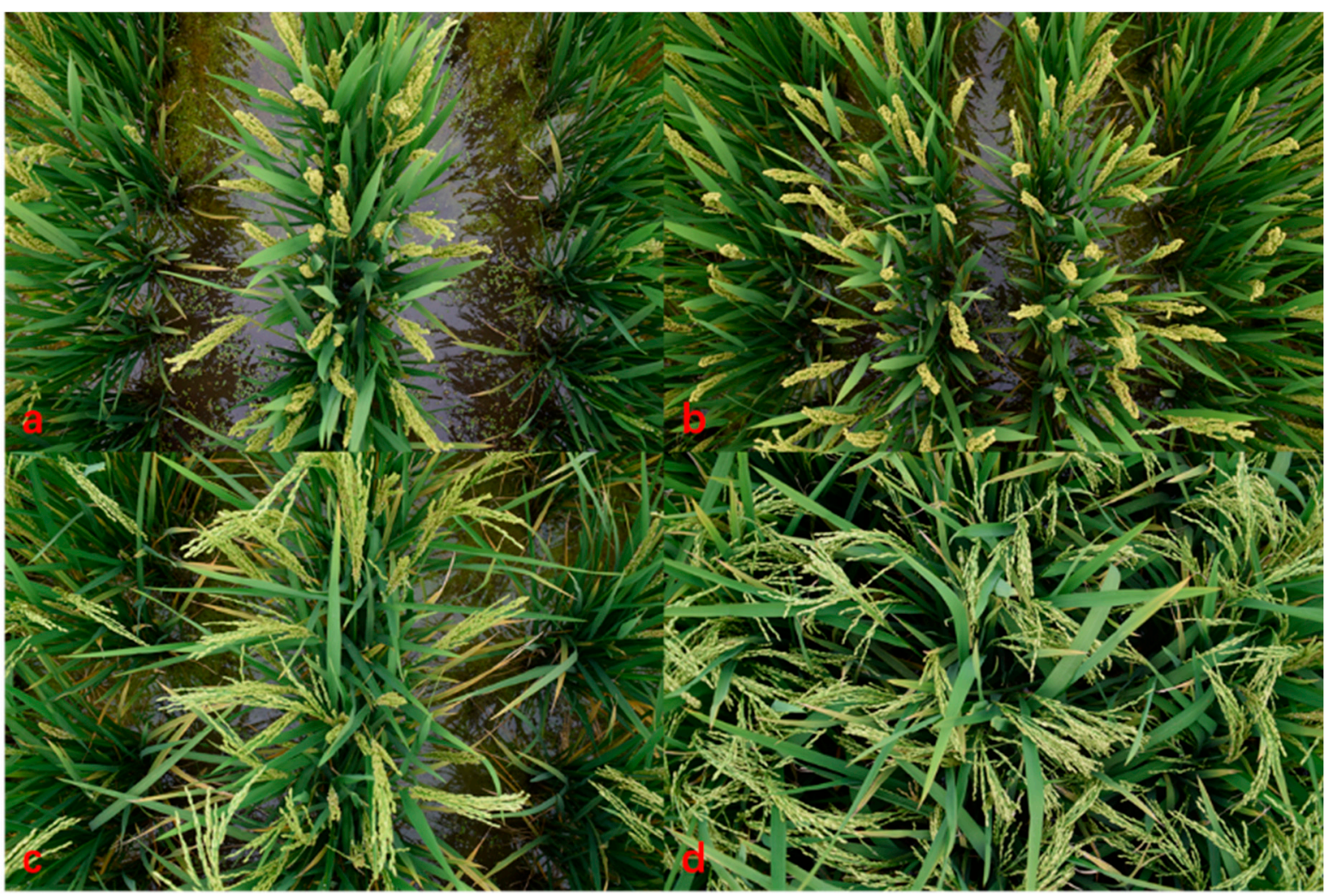

Figure 5. Rice canopy under different treatments. a, b, c, and $\mathbf{d}$ represent V3D4, V3D2, V4D4, and V4D2, respectively.

\subsubsection{Development of the Panicle-Adjusted Renormalized Difference Vegetation Index (PRDVI)}

The combination of near-infrared band and red-edge bands has performed well in the prediction of LAI [34-37]. The key difference between panicles and leaves is their internal structures and components (such as chlorophyll), and it caused large differences in canopy reflectance in the visible and near-infrared regions, before and after panicle removal (detailed in Section 3.1.). However, the red-edge band was stable (Figure 3). Therefore, the red-edge band was selected to replace the red band in the RDVI.

A clear linear relationship was observed between the near-infrared band reflectance of panicles and the red-edge band among rice varieties with different panicle types. The maximum values of the red-edge and the near-infrared reflectance of panicles were much larger than those of the canopy with the panicles that were removed (Figure 6a). Therefore, a "rice panicle line" was constructed to obtain 
the panicle adjustment factor $(\theta)$ by using the near-infrared and red-edge spectral reflectance of rice panicles (Figure 6b).

$$
\rho(\text { nir })=a \rho(\text { red edge })+b
$$

where $\mathrm{a}$ and $\mathrm{b}$ are the slope and intercept of the rice panicle line, respectively, and they are mainly affected by the panicle type and maturity. The panicle adjustment factor $(\theta=b / a)$ was used to modify the near-infrared band in the RDVI. Then, the PRDVI was defined, as follows:

$$
\text { PRDVI }=\frac{((1+\theta) \mathrm{NIR}-\mathrm{RE})}{\sqrt{(\mathrm{NIR}+\mathrm{RE})}}
$$

where NIR and RE are the average reflectance of the near-infrared band $(841-876 \mathrm{~nm})$ and the red-edge band $(720-740 \mathrm{~nm}) ; \theta$ is the panicle adjustment factor, which is the ratio between the intercept and the slope of the rice panicle line. In the pre-heading stage, $\theta$ is 0 , and the PRDVI is equivalent to the RDVI, with its red band being replaced by the red-edge band.

a

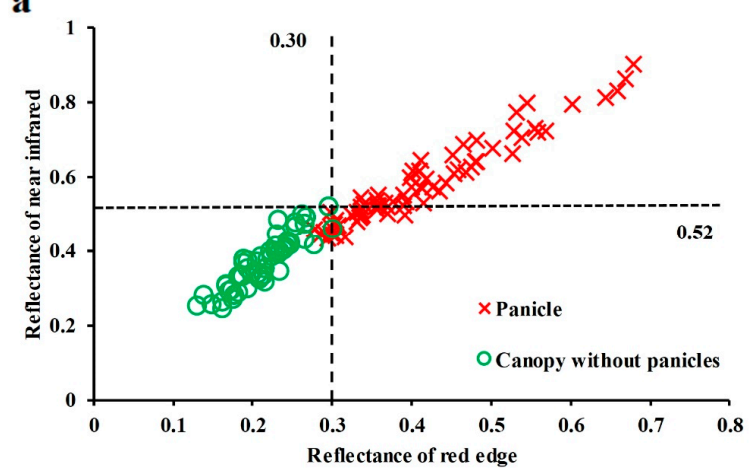

b

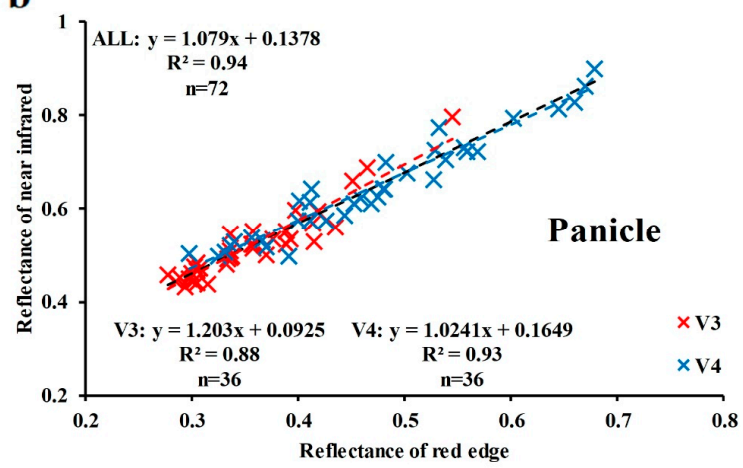

Figure 6. Plot of near-infrared band (NIR) reflectance versus red-edge reflectance (a) and the panicle line developed in this study (b). The dotted lines in (a) indicate the maximum values of the red-edge and near-infrared reflectance of the panicle-removed canopy.

\subsection{Data Analysis and Application}

Data from the five experiments were divided into 12 different data set combinations that were based on different growth stages (pre-heading stages: data set 1 and 9; post-heading stages: data set 2 and 10; All stages: data set 3 and 11), different remote sensing platforms (FieldSpec4: data set 1-11; UAV: data set 12), and the rice canopy with (data set 5) or without panicles (data set 6) (Table 2). Each data set included two types of rice (japonica and indica). Data sets 1-3 were used to evaluate the performance of different VIs in LAI estimation at different growth stages. Data set 4 was used to construct the rice panicle line. Data sets 5-8 were used to evaluate the effect of panicles on LAI estimation accuracy, and data sets 9-12 were used to test and evaluate the newly developed vegetation index. In the present study, VI performance in LAI estimation was evaluated while using the coefficient of determination $\left(\mathrm{R}^{2}\right)$, root-mean-square error (RMSE), and relative root-mean-square error (rRMSE). The formulae are as follows:

$$
\begin{gathered}
R^{2}=1-\frac{\sum_{i=1}^{n}\left(P_{i}-O_{i}\right)^{2}}{\sum_{i=1}^{n}\left(P_{i}-O_{i}\right)^{2}} \\
R M S E=\sqrt{\frac{\sum_{i=1}^{n}\left(P_{i}-O_{i}\right)^{2}}{n}} \\
r R M S E=\sqrt{\frac{\sum_{i=1}^{n}\left(P_{i}-O_{i}\right)^{2}}{n}} \times \frac{100}{\overline{O_{i}}}
\end{gathered}
$$


where $O_{i}$ and $P_{i}$ are the observed value and predicted value, $\mathrm{n}$ is the number of samples, and $\overline{O_{i}}$ is the average of $O_{i}$.

Table 2. Summary description of the datasets.

\begin{tabular}{cccccc}
\hline \multirow{2}{*}{ Dataset } & \multirow{2}{*}{ Year } & Description & \multicolumn{3}{c}{ Number of Samples } \\
\cline { 3 - 5 } & & Japonica & Indica & Total \\
\hline 1 & & Pre-heading stages & 159 & 162 & 321 \\
2 & Post-heading stages & 120 & 120 & 240 \\
3 & All stages & 279 & 282 & 561 \\
4 & Panicles & 36 & 36 & 72 \\
5 & \multirow{2}{*}{$2015-2016$} & Original canopy & 36 & 36 & 72 \\
6 & & Canopy without panicles & 36 & 72 \\
7 & & Pre-heading + Canopy without panicles & 195 & 198 & 393 \\
8 & & Post-heading + Original canopy & 156 & 156 & 312 \\
\hline 9 & & Pre-heading stages & 279 & 282 & 561 \\
10 & $2013-2016$ & Post-heading stages & 210 & 210 & 420 \\
11 & & All stages & 489 & 492 & 981 \\
\hline 12 & 2015 & UAV data & 36 & 36 & 72 \\
\hline
\end{tabular}

The names, formulae, and references for the VIs that were used in this study are presented in Table 3. The mean reflectance values of the 841-876, 720-740, 620-670, 550-570, and 459-479 nm ranges were used as the reflectance in the near-infrared, red-edge, red, green, and blue bands, respectively.

Table 3. Spectral vegetation indices used in this study. The coefficient of determination of leaf area index for different spectral indices was calculated using the spectral data of the entire canopy and the canopy without panicles.

\begin{tabular}{|c|c|c|c|c|}
\hline \multirow[b]{2}{*}{ Vegetation Index } & \multirow[b]{2}{*}{ Formula $^{a}$} & \multicolumn{2}{|c|}{ Coefficient of Determination } & \multirow[b]{2}{*}{ Reference } \\
\hline & & $\begin{array}{l}\text { Entire } \\
\text { Canopy }\end{array}$ & $\begin{array}{l}\text { Canopy without } \\
\text { Panicles }\end{array}$ & \\
\hline DI & $\lambda_{1}-\lambda_{2} \mathrm{~b}$ & 0.66 & 0.76 & [10] \\
\hline SR & $R_{\text {nir }} / R_{\text {red }}$ & 0.38 & 0.31 & [10] \\
\hline NDVI & $\left(R_{\text {nir }}-R_{\text {red }}\right) /\left(R_{\text {nir }}+R_{\text {red }}\right)$ & 0.37 & 0.29 & [38] \\
\hline GNDVI & $\left(R_{\text {nir }}-R_{\text {green }}\right) /\left(R_{\text {nir }}+R_{\text {green }}\right)$ & 0.49 & 0.36 & [39] \\
\hline RDVI & $\left(R_{800}-R_{670}\right) / \sqrt{\left(R_{800}+R_{670}\right)}$ & 0.43 & 0.58 & [14] \\
\hline MSR & $\left(\frac{R_{800}}{R_{670}}-1\right) / \sqrt{\left(\frac{R_{800}}{R_{670}}+1\right)}$ & 0.33 & 0.28 & [15] \\
\hline Green WDRVI & $\frac{1-\alpha}{1+\alpha}+\frac{\alpha \times R_{\text {nii }}-R_{\text {green }}}{\alpha \times R_{\text {nir }}+R_{\text {green }}} \mathrm{c}$ & 0.51 & 0.39 & {$[40,41]$} \\
\hline Red Edge WDRVI & $\frac{1-\alpha}{1+\alpha}+\frac{\alpha \times R_{\text {nir }}-R_{\text {red edge }}}{\alpha \times R_{\text {nir }}+R_{\text {red edge }}} \mathrm{c}$ & 0.60 & 0.43 & {$[40,41]$} \\
\hline SAVI & $(1+L)\left(R_{800}-R_{670}\right) /\left(R_{800}+R_{670}+L\right)^{\mathrm{d}}$ & 0.44 & 0.57 & {$[16]$} \\
\hline OSAVI & $(1+Y)\left(R_{800}-R_{670}\right) /\left(R_{800}+R_{670}+Y\right) \mathrm{e}$ & 0.40 & 0.53 & [17] \\
\hline TVI & $\begin{array}{c}0.5\left[120\left(R_{750}-R_{550}\right)-200\left(R_{670}-R_{550}\right)\right] \\
1.5\left[1.2\left(R_{800}-R_{550}\right)-2.5\left(R_{670}-R_{550}\right)\right]\end{array}$ & 0.28 & 0.37 & [42] \\
\hline MTVI2 & $\sqrt{\sqrt{\left(2 R_{800}+1\right)^{2}-\left(6 R_{800}-5 \sqrt{R_{670}}\right)-0.5}}$ & 0.38 & 0.52 & [20] \\
\hline EVI & $\frac{2.5\left(R_{\text {nir }}-R_{\text {red }}\right)}{\left(R_{\text {nir }}+6 R_{\text {red }}-7.5 R_{\text {blue }}+1\right)}$ & 0.51 & 0.61 & [43] \\
\hline $\mathrm{CI}_{\text {red edge }}$ & $\left(R_{\text {nir }} / R_{\text {red edge }}\right)-1$ & 0.60 & 0.43 & [44] \\
\hline $\mathrm{CI}_{\text {green }}$ & $\left(R_{\text {nir }} / R_{\text {green }}\right)-1$ & 0.50 & 0.39 & [44] \\
\hline NDRE & $\left(R_{\text {nir }}-R_{\text {red edge }}\right) /\left(R_{\text {nir }}+R_{\text {red edge }}\right)$ & 0.41 & 0.35 & [45] \\
\hline
\end{tabular}

a In all formulae, $\mathrm{R}$ is the reflectance, and the subscripts "nir", "red edge", "red", "green", and "blue", as well as different three-digit numbers, indicate the spectral bands. The mean reflectance values of the $841-876,720-740$, $620-670,550-570$, and $459-479 \mathrm{~nm}$ ranges were used as the reflectance of the NIR, red-edge, red, green, and blue bands, respectively. ${ }^{b}$ In this study, $\lambda_{1}=R_{\text {nir }}, \lambda_{2}=R_{\text {red edge }}{ }^{c}$ In the two variants of the wide dynamic range vegetation index (WDRVI), $\alpha$ was $0.1 .{ }^{\mathrm{d}} \mathrm{L}$ is a soil adjustment factor; here, $\mathrm{L}=0.5$, according to Huete [16]. ${ }^{\mathrm{e}} \mathrm{Y}$ is a soil adjustment factor; here, $\mathrm{Y}=0.16$, according to Rondeaux et al. [17]. 


\section{Results}

\subsection{Influence of Panicles on the Reflectance of Rice Canopy}

Figure 3 shows that rice canopy reflectance markedly changed after the removal of the panicle layer. The relative variation rates (\%) between $R_{\text {original canopy }}$ and $R_{\text {canopy without panicles }}$ was from $-65 \%$ to $75 \%$ for different bands and different treatments. In general, $R_{\text {canopy without panicles of } V 3 \text { was }}$ influenced more by different planting densities, and the effect of the $\mathrm{N}$ rate varied with the rice varieties and bands. In the $450-730 \mathrm{~nm}$ range, $\mathrm{R}_{\text {canopy without panicles }}$ was lower than $\mathrm{R}_{\text {original canopy }}$ in all the treatments. In addition, the decrease in V4 was less than that in V3. The attenuation range of the two varieties (V3, V4) decreased with the decrease in planting density for the same $\mathrm{N}$ level, and it decreased with the increase in $\mathrm{N}$ fertilization for similar planting densities. Although the difference between

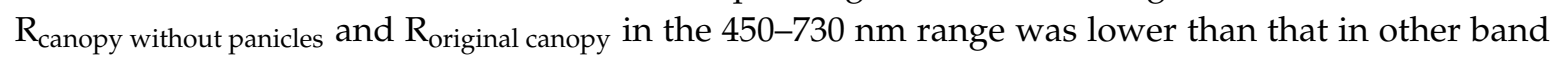
ranges, the relative variation rate of this band range was higher, especially in the red band at $670 \mathrm{~nm}$.

In the 730-1350 $\mathrm{nm}$ range, $R_{\text {canopy without panicles }}$ was lower than $R_{\text {original canopy }}$ in all V3 treatments

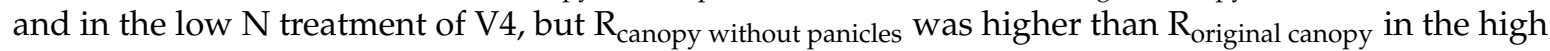
$\mathrm{N}$ treatment of V4. The difference between $\mathrm{R}_{\text {canopy without panicles }}$ and $\mathrm{R}_{\text {original canopy }}$ in this band range still decreased with decreasing planting density. In this band range, although the relative variation rate of the reflectance was smaller than that in the other bands, there is a big difference between before and after panicle removal due to of the higher reflectance of the short-wave near-infrared band.

The red-edge position in the rice canopy spectra before and after panicle removal did not change, except in the maturing stage (117 DAT) (Table 4).

Table 4 . The red edge position of $R_{\text {original canopy }}$ and $R_{\text {canopy without panicles }}$ for different treatments and growth stages. Data were collected in 2015.

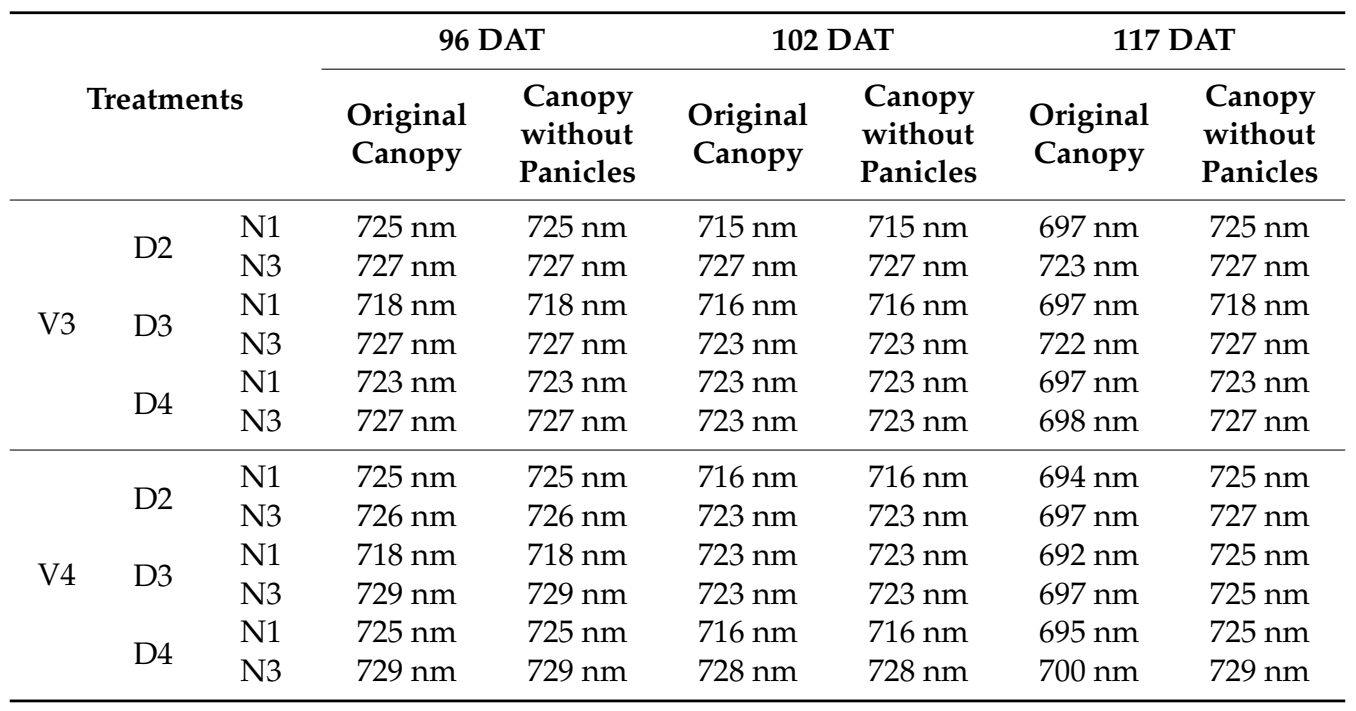

\subsection{Influence of Panicles on LAI Estimation Accuracy}

3.2.1. Relationship between LAI and the Reflectance of Rice Canopy before and after the Removal of Panicles

VIs that are commonly used to estimate LAI were calculated while using $\mathrm{R}_{\text {canopy without panicles }}$ and $\mathrm{R}_{\text {original canopy, }}$ and the correlations between the VIs and LAI were analyzed (Table 3). Figure 7 shows the relative variation rate of the estimation accuracy. The results show that LAI estimation accuracy in some VIs (DI, SAVI, RDVI, MTVI2, TVI, EVI, OSAVI) improved when using $\mathrm{R}_{\text {canopy without panicles, }}$ within marked improvements in SAVI, RDVI, MTVI2, and TVI. However, there was a decline in LAI estimation accuracy with the use of $\mathrm{R}_{\text {canopy without panicles }}$ for the chlorophyll index red edge $\left(\mathrm{CI}_{\text {red edge }}\right)$, 
chlorophyll index green $\left(\mathrm{CI}_{\text {green }}\right)$, green wide dynamic range vegetation index $\left(\mathrm{WDRVI}_{\text {green }}\right)$, red-edge wide-range vegetation index $\left(W^{2} \mathrm{VII}_{\text {red edge }}\right)$, NDVI, normalized difference red edge (NDRE), green normalized difference vegetation index (GNDVI), SR, and MSR. The decreased accuracy was particularly pronounced for the $\mathrm{CI}_{\text {red edge }}, \mathrm{CI}_{\text {green }}, \mathrm{WDRVI}_{\text {green }}, \mathrm{WDRVI}_{\text {red edge, }}$ and GNDVI.

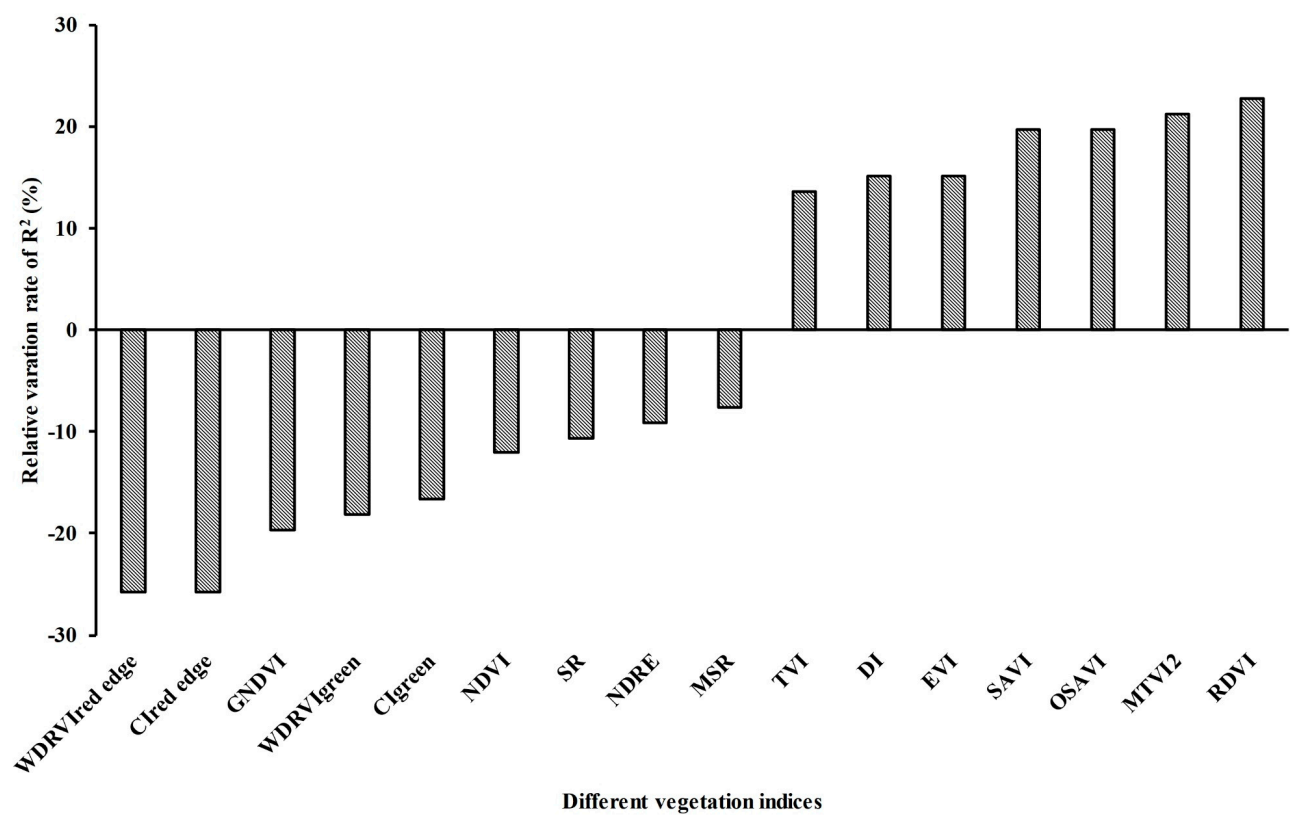

Figure 7. Relative variation rate $\left(\mathrm{R}_{\mathrm{V}}, \%\right)$ of LAI estimation accuracy (the coefficient of determination, $R^{2}$ ) before (data set 5) and after panicle removal (data set 6). A positive $R_{v}$ value indicates that $R^{2}$ increased after panicle removal, whereas a negative value indicates a decrease.

Different vegetation indices exhibited different responses to panicle removal in different experimental treatments (Figure 8). The VIs (DI, SAVI, RDVI, MTVI2, TVI, EVI, and OSAVI), whose estimation accuracy increased after the removal of panicles changed slightly before and after the removal of panicles. On the contrary, the VIs $\left(\mathrm{CI}_{\text {red edge }}, \mathrm{CI}_{\text {green }}, \mathrm{WDRVI} \mathrm{I}_{\text {green }}, \mathrm{WDRVI}_{\text {red edge }}, \mathrm{NDVI}\right.$, NDRE, GNDVI, MSR, and SR) whose estimation accuracy decreased after the removal of panicles varied greatly between the two conditions (i.e., with and without panicles). Variations in the VIs of V3 were significantly larger than those of V4.

Five representative two-band VIs (DI, SAVI, RDVI, CI, WDRVI) were selected to conduct full-band (350-2500 nm) sensitivity analyses of LAI while using $R_{\text {canopy without panicles }}$ and $R_{\text {original canopy }}$ (Figure 9). The results show that the LAI sensitivity ranges of VIs calculated by $\mathrm{R}_{\text {canopy without panicles }}$ and $R_{\text {original canopy }}$ were different. For the DI, SAVI, and RDVI, LAI sensitivity in the 750-1350, 1450-1780, 1970-2350 $(\lambda 1)$, and 550-680 nm ( $\lambda 2)$ combination significantly increased. For the CI and WDRVI, the range of sensitive bands significantly shifted toward the long-wave spectrum. There was an increase in LAI sensitivity in the 1450-1780, 1970-2350 ( $\lambda 1)$, and 550-680 $\mathrm{nm}(\lambda 2)$ combination. However, the sensitivity decreased in the 750-1350 $(\lambda 1)$ and 550-680 $\mathrm{nm}(\lambda 2)$ combination.

Table 5 shows that the optimal band combination (OBC) for different vegetation indices that were used to estimate LAI was relatively uniform and was the near-infrared and red-edge band combination. Before the removal of panicles, RDVI $(951,733)$, RDVI $(897,745)$, and RDVI $(1157,724)$ had the best performance in LAI estimation for V3, V4, and V3+V4, respectively. After the removal of panicles, RDVI $(958,732)$, RDVI $(931,739)$, and $\operatorname{RDVI}(996,732)$ performed the best. In japonica rice (V3), the near-infrared band of the OBC significantly shifted toward the long-wave spectrum after the removal of panicles. Conversely, it shifted toward the short-wave spectrum in indica rice (V4). 

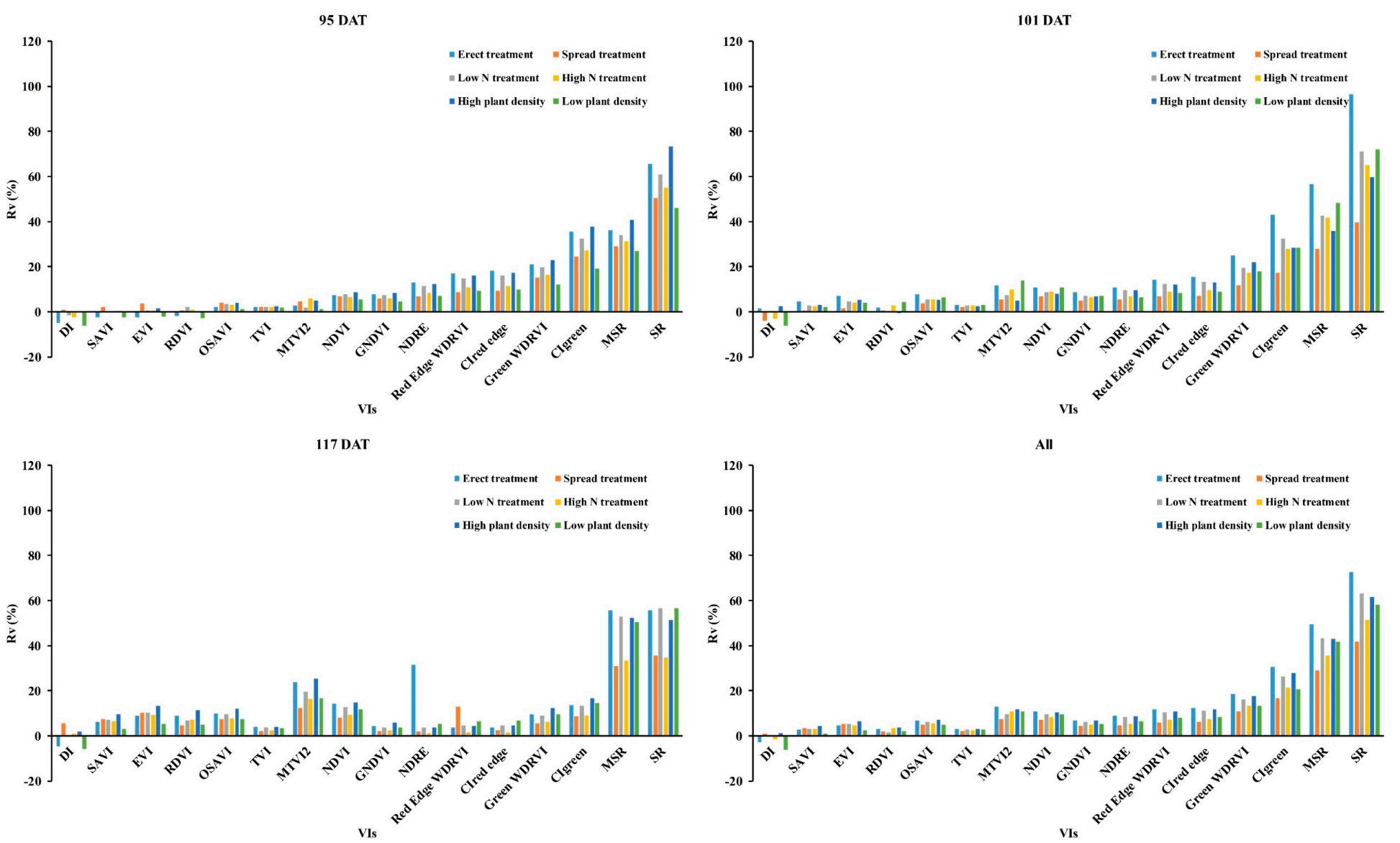

Figure 8. Relative variation rates $\left(R_{V}, \%\right)$ of different vegetation indices in response to the removal of panicles from rice canopies with different treatments. $R_{\mathrm{V}}$ is the percentage of the vegetation index after panicle removal minus the vegetation index of the original canopy over the absolute value of the vegetation index of the original canopy. A positive $R_{\mathrm{V}}$ value indicates an increase in the vegetation index after panicle removal, whereas a negative value indicates a decrease. Erect treatment $=$ erect-type variety (V3), 16.66 plants $\mathrm{m}^{-2}, 300 \mathrm{~kg} \mathrm{~N}$ ha $^{-1}$; Spread treatment $=$ spread-type variety $(\mathrm{V} 4), 16.66 \mathrm{plants} \mathrm{m}^{-2}, 300 \mathrm{~kg} \mathrm{~N}^{-1} ;$ Low N treatment $=$ spread-type variety (V4), 22.22 plants $\mathrm{m}^{-2}, 100 \mathrm{~kg} \mathrm{~N} \mathrm{ha}^{-1} ;$ High N treatment = spread-type variety (V4), 22.22 plants m ${ }^{-2}, 300 \mathrm{~kg} \mathrm{~N} \mathrm{ha}^{-1} ; \mathrm{High}^{-2}$ plant density = erect-type variety (V3), 22.22 plants $\mathrm{m}^{-2}, 300 \mathrm{~kg} \mathrm{~N} \mathrm{ha}^{-1}$; Low plant density = erect-type variety (V3), 13.33 plants $\mathrm{m}^{-2}, 300 \mathrm{~kg} \mathrm{~N} \mathrm{ha}^{-1}$. 

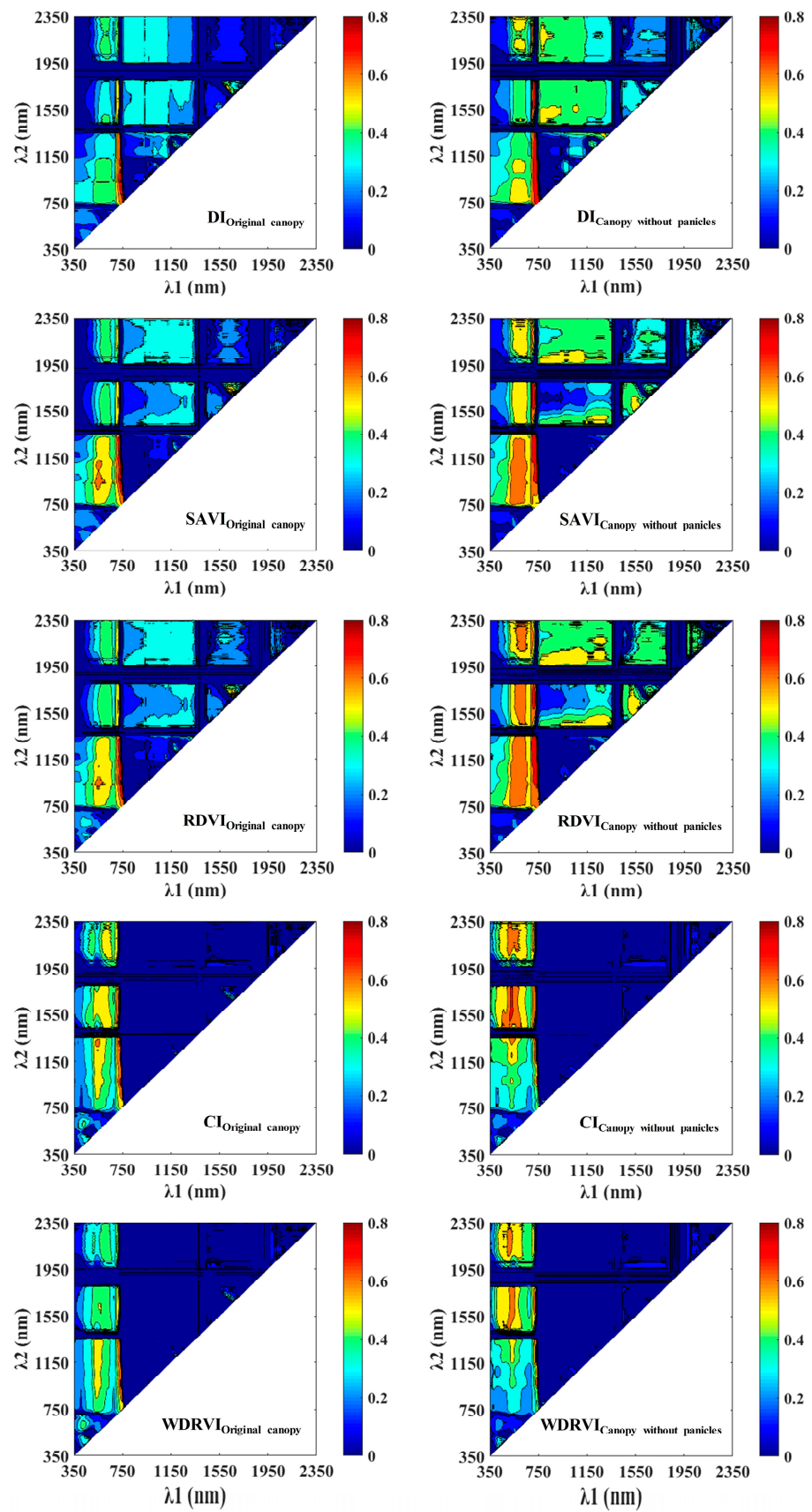

Figure 9. Correlations between DI, SAVI, RDVI, CI, and WDRVI, and rice canopy LAI that were

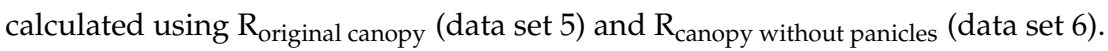

3.2.2. Relationship between LAI and VIs during the Pre-Heading Stage, Post-Heading Stage, and Whole Growth Stage

Figure 10 shows that the sensitive band range of LAI markedly decreased after the heading stage, and the accuracy of LAI estimation decreased for all VIs. In the pre-heading stage, RDVI $(855,749)$ performed best when the two varieties were simultaneously considered, with $\mathrm{R}^{2}$, RMSE, and rRMSE values of $0.76,1.23\left(\mathrm{~m}^{2} / \mathrm{m}^{2}\right)$, and $27.39 \%$. In the post-heading stage, the near-infrared band of the OBC significantly shifted in the short-wave direction in japonica rice (V1, V3). Conversely, it shifted in the long-wave direction in indica rice $(\mathrm{V} 2, \mathrm{~V} 4)$. DI $(976,733)$ performed best when the two varieties were simultaneously considered, with $\mathrm{R}^{2}$, RMSE, and rRMSE were $0.60,1.41\left(\mathrm{~m}^{2} / \mathrm{m}^{2}\right)$, and $28.24 \%$. A comparison of the calculated results using data sets 7-8 and data sets 1-2 (Table 5) reveals that the $\mathrm{OBC}$ and $\mathrm{R} 2$ of the five VIs did not significantly change. 
Table 5. The determination coefficient $\left(\mathrm{R}^{2}\right)$, optimal band combination (OBC), root-mean-square error (RMSE) and relative root mean squared error (rRMSE) for LAI estimations while using five vegetation indices and different data sets.

\begin{tabular}{|c|c|c|c|c|c|c|c|c|c|c|c|c|c|c|c|c|c|c|c|c|c|}
\hline \multirow[b]{2}{*}{ Cultivar } & \multirow[b]{2}{*}{ Data } & \multicolumn{4}{|c|}{ DI } & \multicolumn{4}{|c|}{ SAVI } & \multicolumn{4}{|c|}{ RDVI } & \multicolumn{4}{|c|}{ CI } & \multicolumn{4}{|c|}{ WDRVI } \\
\hline & & $\mathbf{R}^{2}$ & ОВС & RMSE & $\begin{array}{c}\text { rRMSE } \\
(\%)\end{array}$ & $\mathrm{R}^{2}$ & ОВС & RMSE & $\begin{array}{c}\text { rRMSE } \\
(\%)\end{array}$ & $\mathrm{R}^{2}$ & ОВС & RMSE & $\begin{array}{c}\text { rRMSE } \\
(\%)\end{array}$ & $\mathrm{R}^{2}$ & ОВС & RMSE & $\begin{array}{l}\text { rRMSE } \\
(\%)\end{array}$ & $\mathrm{R}^{2}$ & ОВС & RMSE & $\begin{array}{l}\text { rRMSE } \\
(\%)\end{array}$ \\
\hline \multirow{10}{*}{$\begin{array}{c}\text { All } \\
(\mathrm{V} 1+\mathrm{V} 2+\mathrm{V} 4+\mathrm{V} 4)\end{array}$} & 1 & 0.73 & 851,756 & 1.15 & 27.88 & 0.76 & 854,752 & 1.09 & 26.42 & 0.75 & 851,753 & 1.09 & 26.43 & 0.72 & 854,751 & 1.17 & 28.24 & 0.72 & 854,751 & 1.17 & 28.27 \\
\hline & 2 & 0.59 & 774,744 & 1.24 & 29.68 & 0.60 & 934,723 & 1.23 & 29.39 & 0.60 & 934,724 & 1.23 & 29.27 & 0.49 & 955,724 & 1.39 & 33.21 & 0.50 & 955,724 & 1.38 & 33.06 \\
\hline & 3 & 0.63 & 785,753 & 1.28 & 30.76 & 0.65 & 897,738 & 1.25 & 30.03 & 0.65 & 851,742 & 1.25 & 29.94 & 0.58 & 853,742 & 1.36 & 32.66 & 0.59 & 897,739 & 1.35 & 32.52 \\
\hline & 5 & 0.66 & 958,732 & 0.88 & 22.30 & 0.68 & 958,732 & 0.87 & 22.14 & 0.69 & 951,733 & 0.85 & 21.74 & 0.55 & 958,734 & 1.06 & 27.06 & 0.55 & 958,734 & 1.06 & 27.06 \\
\hline & 6 & 0.70 & 934,731 & 0.93 & 23.62 & 0.70 & 974,733 & 0.90 & 23.01 & 0.71 & 958,732 & 0.89 & 22.63 & 0.53 & 974,737 & 1.08 & 27.58 & 0.54 & 974,737 & 1.08 & 27.56 \\
\hline & 7 & 0.69 & 851,750 & 1.17 & 28.57 & 0.72 & 867,748 & 1.11 & 27.07 & 0.73 & 855,749 & 1.11 & 26.98 & 0.67 & 854,748 & 1.20 & 29.36 & 0.67 & 854,748 & 1.21 & 29.39 \\
\hline & 8 & 0.59 & 774,744 & 1.19 & 28.94 & 0.60 & 934,724 & 1.92 & 46.61 & 0.61 & 934,725 & 1.1 & 28.28 & 0.50 & 960,7 & 1.3 & & 0.50 & 960,7 & 1.33 & 32.17 \\
\hline & 9 & 0.76 & 851,753 & 1.24 & 27.58 & 0.74 & 779,749 & 1.27 & 28.45 & 0.76 & 855,749 & 1.23 & 27.39 & 0.70 & 779,749 & 1.37 & 30.65 & 0.70 & 779,749 & 1.37 & 30.69 \\
\hline & 10 & 0.60 & 976,733 & 1.41 & 28.24 & 0.53 & 1490,708 & 1.53 & 30.46 & 0.60 & 961,729 & 1.42 & 28.39 & 0.56 & 1490,708 & 1.49 & 29.67 & 0.57 & 1490,708 & 1.48 & 29.61 \\
\hline & 11 & 0.66 & 849,746 & 1.40 & 29.76 & 0.64 & 897,741 & 1.44 & 30.59 & 0.65 & 896,742 & 1.42 & 30.15 & 0.57 & 930,740 & 1.59 & 33.79 & 0.57 & 930,740 & 1.59 & 33.78 \\
\hline \multirow{10}{*}{$\begin{array}{l}\text { Japonica rice } \\
(\mathrm{V} 1+\mathrm{V} 3)\end{array}$} & 1 & 0.70 & 786,758 & 0.77 & 25.41 & 0.77 & 801,758 & 0.94 & 31.11 & 0.77 & 801,758 & 0.67 & 22.26 & 0.80 & 802,757 & 0.62 & 20.64 & 0.80 & 802,757 & 0.62 & 20.65 \\
\hline & 2 & 0.49 & 7,476 & & 26 & 0.58 & 77 & & & 0.57 & 75,745 & 0.8 & 24 & 0.63 & 77,747 & & & 0.63 & & & 22.23 \\
\hline & 3 & 0.58 & 786,753 & 0.88 & 27.47 & 0.67 & 788,754 & 0.78 & 24.34 & 0.66 & 787,754 & 0.79 & 24.61 & 0.70 & 789,755 & 0.7 & & 0.70 & 789,7 & & 22.99 \\
\hline & 5 & 0.57 & 929,741 & 0.69 & 20.33 & 0.63 & 865,748 & 0.67 & 19.70 & 0.63 & 897,745 & 0.66 & 19.55 & 0.54 & 822,752 & 0.77 & 22.75 & 0.54 & 822,752 & 0.77 & 22.74 \\
\hline & 6 & 0.63 & 933,737 & 0.74 & 21.89 & 0.65 & 931,739 & 0.69 & 20.31 & 0.66 & 931,739 & 0.69 & 20.23 & 0.51 & 930,740 & 0.80 & 23.49 & 0.51 & 930,740 & 0.79 & 23.45 \\
\hline & 7 & 0.66 & 796,758 & 0.78 & 25.39 & 0.73 & 802,757 & 0.70 & 22.68 & 0.73 & 802,757 & 0.71 & 22.83 & 0.75 & 810,757 & 0.6 & & 0.75 & 810,757 & 0.68 & 22.14 \\
\hline & 8 & 0.46 & 776,746 & 0.91 & 26. & 0.55 & 7,747 & 0.8 & 24.19 & 0.54 & 77,747 & 0.8 & & 0.56 & 788,7 & & & 0.56 & 788,7 & & 23.88 \\
\hline & 9 & 0.74 & 786,7 & 0. & & 0.78 & 789,755 & & & 0.78 & 789,754 & & & 0.79 & 789, & & & & & & 22.54 \\
\hline & 10 & 0.49 & 510,480 & 1.04 & 25.50 & 0.54 & 934,733 & 0.99 & 24.2 & 0.54 & 34,732 & 0.99 & 24. & 0.60 & 934,731 & 0.92 & 22. & 0.60 & 934,731 & 0.92 & 22.50 \\
\hline & 11 & 0.61 & 787,756 & 1.00 & 27.50 & 0.69 & 788,756 & 0.89 & 24.45 & 0.69 & 788,756 & 0.90 & 24.75 & 0.72 & 823,749 & 0.85 & 23.39 & 0.72 & 823,749 & 0.85 & 23.38 \\
\hline \multirow{8}{*}{$\begin{array}{l}\text { Indica rice } \\
(\mathrm{V} 2+\mathrm{V} 4)\end{array}$} & 1 & 0.74 & 813,763 & 1.19 & 22.65 & 0.79 & 851,75 & 1.07 & 20.3 & 0.78 & 851,756 & 1.09 & 20.85 & 0.80 & 849,753 & 1.03 & 19.64 & 0.80 & 849,753 & 1.03 & 19.64 \\
\hline & 2 & 0.62 & 1575,719 & 1.37 & 27.79 & 0.67 & 955,727 & 1.28 & 25.96 & 0.66 & 955,727 & 1.28 & 26.10 & 0.66 & 965,728 & 1.29 & 26.11 & 0.67 & 965,728 & 1.28 & 26.06 \\
\hline & 3 & 0.60 & 786,756 & 1.44 & 28.25 & 0.67 & 785,755 & 1.31 & & 0.66 & 785,755 & 1.32 & 25.90 & & & & & & & & 25.81 \\
\hline & 7 & 0.67 & 795,758 & 1.30 & 25.48 & 0.74 & 851,749 & 1.14 & 22.43 & 0.73 & 794,758 & 1.16 & 22.81 & 0.75 & 851,748 & 1.13 & 22.12 & 0.75 & 851,748 & 1.13 & 22.13 \\
\hline & 8 & 0.63 & 776,746 & 1.31 & 27.12 & 0.68 & 955,728 & 1.20 & 24.95 & 0.68 & 955,728 & 1.20 & 25.02 & 0.66 & 963,729 & 1.24 & 25.70 & 0.67 & 966,729 & 1.23 & 25.63 \\
\hline & 9 & 0.78 & 813,763 & 1.19 & 21.16 & 0.79 & 796,766 & 1.23 & 21.62 & 0.79 & 796,766 & 1.23 & 21.61 & 0.79 & 795,758 & 1.22 & 21. & 0.79 & 795,758 & 1.22 & 21.55 \\
\hline & 10 & 0.63 & 991,733 & 1.53 & & 0.65 & 992,731 & 1.4 & 24 & 0.66 & 992731 & 1.4 & & 0.58 & 1193,727 & 1.64 & & & 1193,727 & 1.61 & 27.23 \\
\hline & 11 & 0.64 & 795,758 & 1.55 & 26.84 & 0.67 & 18,749 & 1.50 & 25.91 & 0.67 & 847,749 & 1.50 & 25.89 & 0.64 & 848,749 & 1.55 & 26.80 & 0.64 & 848,749 & 1.55 & 26.78 \\
\hline
\end{tabular}



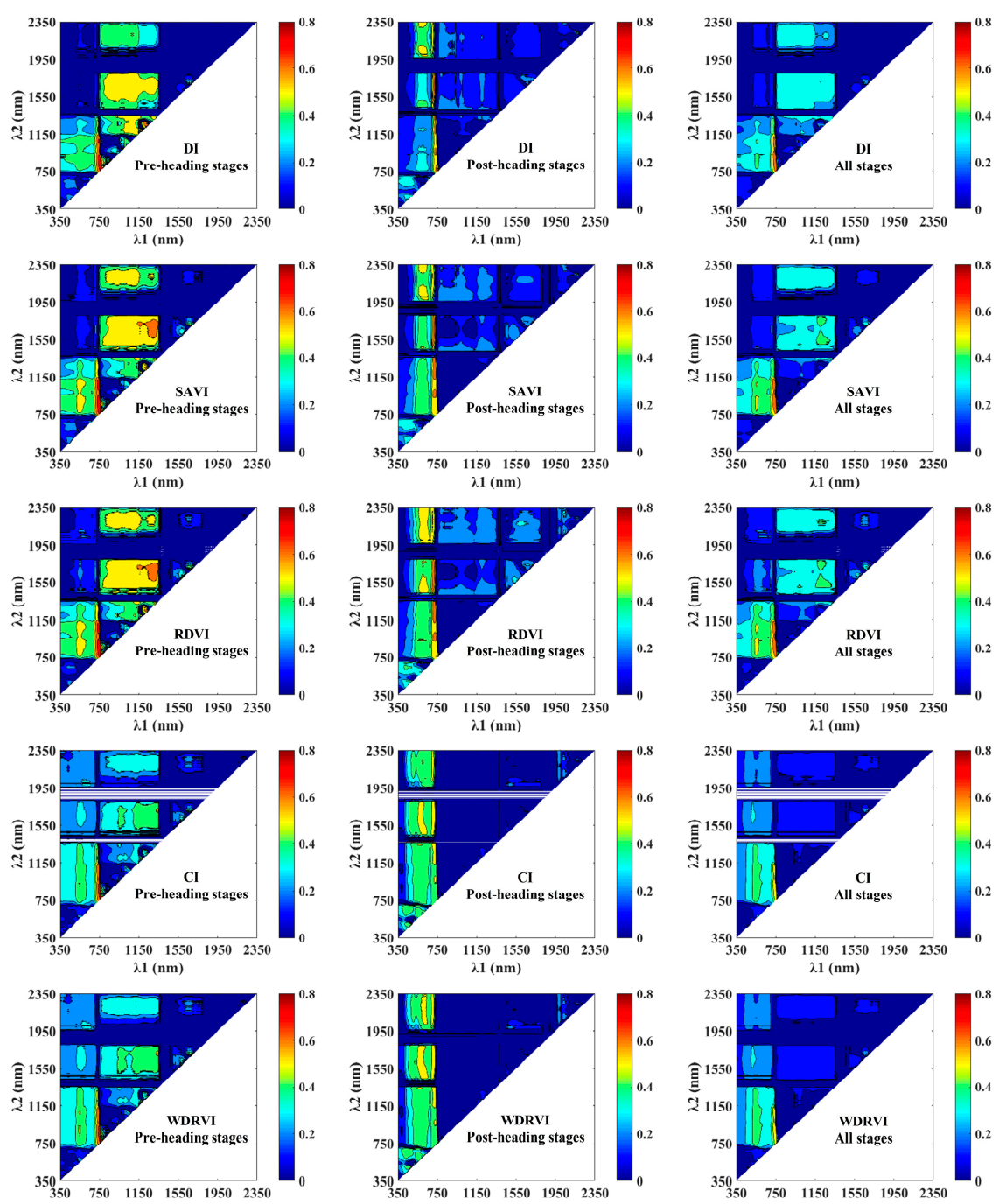

Figure 10. Correlations between the DI, SAVI, RDVI, CI, and WDRVI and rice canopy LAI that were calculated using the reflectance of rice canopy in the pre-heading stages (data set 1), post-heading stages (data set 2), and all stages (data set 3). 
For the entire growth period, the VIs established by combining near-infrared and red-edge bands still performed well in LAI estimation. WDRVI $(823,749)$, RDVI $(847,749)$, and DI $(849,746)$ performed the best for japonica rice, indica rice, and combinations of the two varieties.

\subsection{Relationship between the PRDVI and LAI}

Figure 11 shows that the new vegetation index (PRDVI) could effectively eliminate the influence of panicles and background, and had a close relationship with LAI. The coefficients of determination $\left(\mathrm{R}^{2}\right)$ were $0.68(\mathrm{~V} 3), 0.81(\mathrm{~V} 4)$, and $0.77(\mathrm{~V} 3+\mathrm{V} 4)$. When compared with the optimal narrow-band VIs, including CI $(777,747)$, RDVI $(955,727)$, and RDVI $(934,724)$, the accuracy of LAI estimation using the PRDVI improved by $7.94 \%, 22.73 \%$, and $28.33 \%$, respectively.

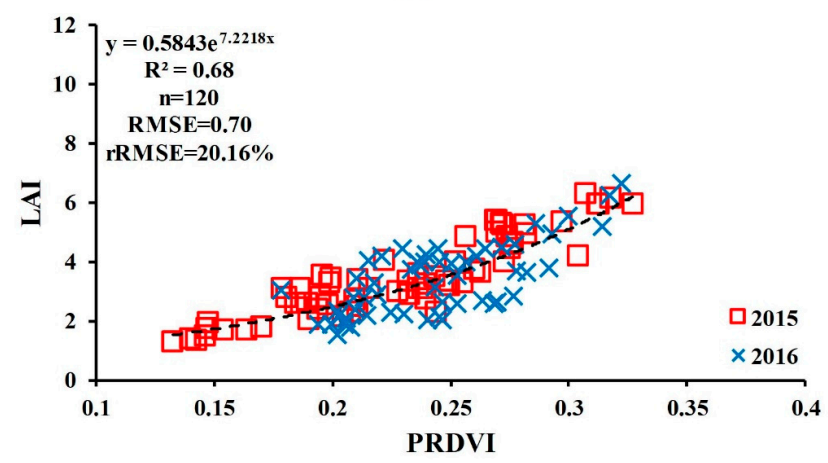

V4

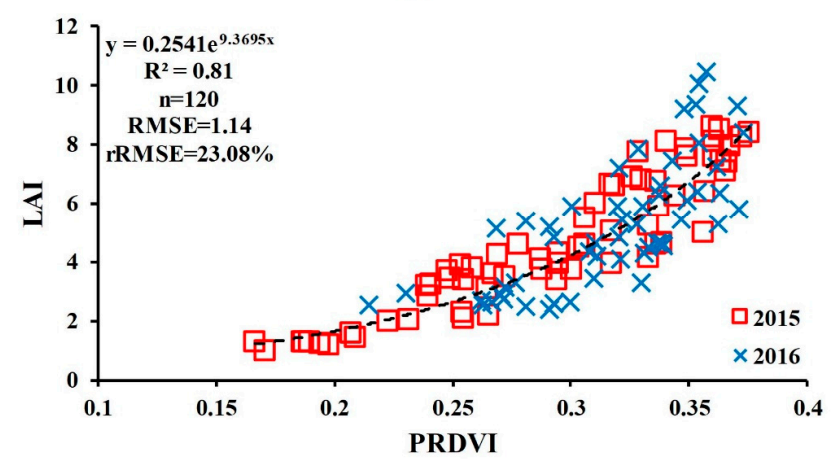

V3+V4

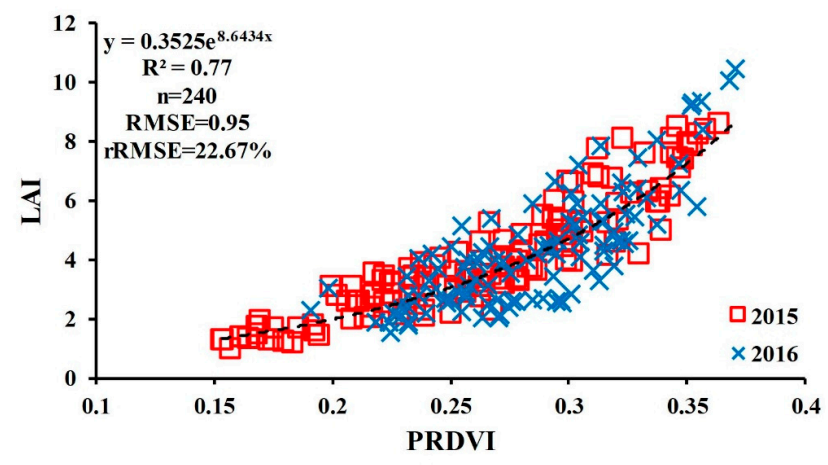

Figure 11. Relationships between LAI and the new vegetation index (Panicle-Adjusted Renormalized Difference Vegetation Index (PRDVI)) (using data set 2). For V3, V4, and V3 + V4, the panicle adjustment coefficients $(\theta)$ were $0.08,0.16$, and 0.13 , respectively.

The applicability of the PRDVI for different years, different varieties, and different growth stages was further tested while using data sets 9-11 (Figure 12). The results show that the PRDVI estimated 
LAI with good accuracy in the post-heading stage and the entire growth stage, with $\mathrm{R}^{2}$ values of 0.72 and 0.71 , respectively. When compared with the optimal narrow-band VIs in the corresponding period, the LAI estimation accuracy using the PRDVI increased by $20.00 \%$ and $7.58 \%$, respectively. Therefore, the PRDVI was able to estimate LAI in the post-heading stage and it improved the accuracy of LAI estimation for the whole growth period of rice.
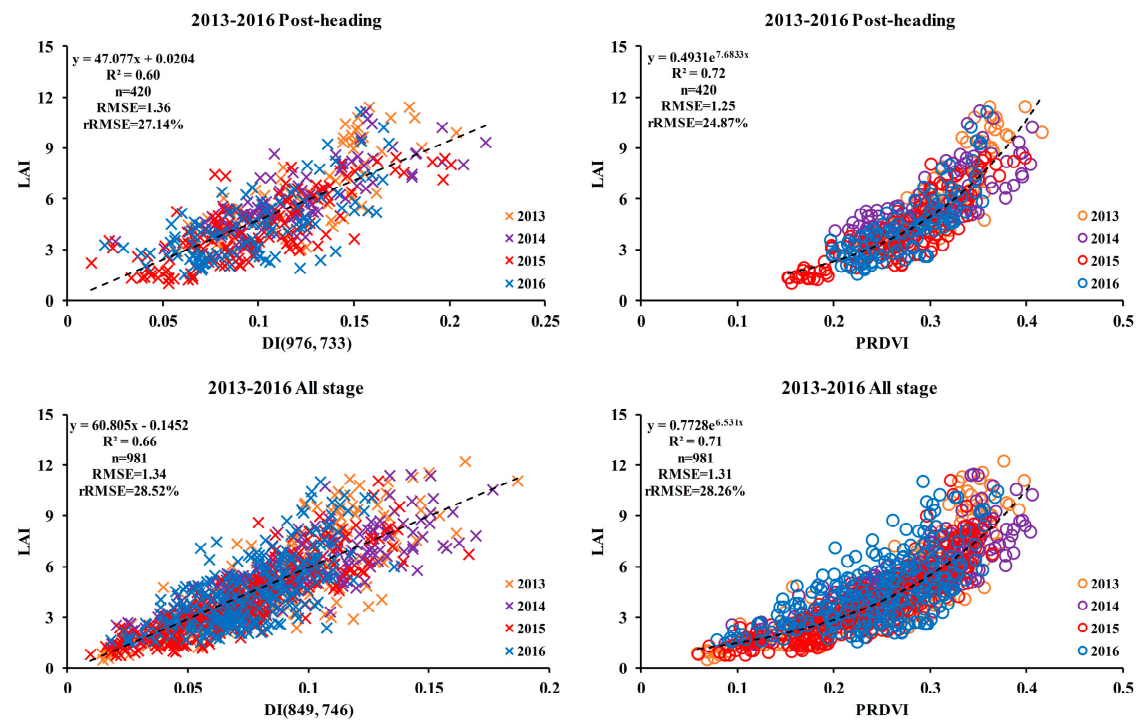

Figure 12. Relationships between LAI and different vegetation indices (using data sets 10 and 11).

The panicle adjustment coefficient $(\theta)$ for the PRDVI was 0.13 .

To verify the applicability of the PRDVI while using different remote sensing platforms, we used multispectral camera data (data set 12) that were obtained by a UAV to compare the LAI estimation performance of the PRDVI with that of other VIs in the post-heading stage (Table 6). The results show that the PRDVI had the highest $R^{2}(0.77)$ and the lowest RMSE $\left(1.01 \mathrm{~m}^{2} / \mathrm{m}^{2}\right)$ as compared with the other VIs. Therefore, in the post-heading stage, the PRDVI performed better in LAI estimation than other VIs while using the UAV platform.

Table 6. Comparison of LAI estimation performance between the PRDVI and other indices using UAV data.

\begin{tabular}{cccccc}
\hline Vegetation Index & Bands $\mathbf{( n m})$ & $\mathbf{R}^{\mathbf{2}}$ & RMSE & rRMSE (\%) & Equation \\
\hline PRDVI & 800,720 & 0.77 & 1.01 & 19.91 & $\mathrm{y}=0.7247 \mathrm{e}^{5.0572 \mathrm{x}}$ \\
DI & 800,720 & 0.70 & 1.32 & 25.87 & $\mathrm{y}=1.2232 \mathrm{e}^{6.9031 \mathrm{x}}$ \\
SR & 800,680 & 0.21 & 1.97 & 43.52 & $\mathrm{y}=2.8269 \mathrm{e}^{0.0087 \mathrm{x}}$ \\
NDVI & 800,680 & 0.32 & 1.99 & 39.12 & $\mathrm{y}=0.0577 \mathrm{e}^{4.6542 \mathrm{x}}$ \\
GNDVI & 800,550 & 0.44 & 1.81 & 35.50 & $\mathrm{y}=0.1675 \mathrm{e}^{4.1117 \mathrm{x}}$ \\
RDVI & 800,680 & 0.53 & 1.65 & 32.42 & $\mathrm{y}=0.4082 \mathrm{e}^{4.7314 \mathrm{x}}$ \\
MSR & 800,680 & 0.38 & 1.84 & 37.30 & $\mathrm{y}=0.3966 \mathrm{x}+2.249$ \\
Green WDRVI & 800,550 & 0.47 & 1.80 & 35.29 & $\mathrm{y}=1.1515 \mathrm{e}^{1.6901 \mathrm{x}}$ \\
Red-Edge WDRVI & 800,720 & 0.73 & 1.38 & 27.07 & $\mathrm{y}=1.1867 \mathrm{e}^{4.8563 \mathrm{x}}$ \\
SAVI & 800,680 & 0.54 & 1.65 & 32.40 & $\mathrm{y}=0.5715 \mathrm{e}^{3.9851 \mathrm{x}}$ \\
OSAVI & 800,680 & 0.51 & 1.66 & 32.54 & $\mathrm{y}=0.2662 \mathrm{e}^{4.0489 \mathrm{x}}$ \\
TVI & $720,680,550$ & 0.00 & 2.38 & 46.74 & $\mathrm{y}=-0.1088 \mathrm{x}+5.7682$ \\
MTVI2 & $800,680,550$ & 0.51 & 1.62 & 32.97 & $\mathrm{y}=8.7745 \mathrm{x}-0.8143$ \\
EVI & $800,680,490$ & 0.57 & 1.59 & 31.32 & $\mathrm{y}=0.6818 \mathrm{e}^{3.4347 \mathrm{x}}$ \\
CI & 800,720 & 0.72 & 1.26 & 24.77 & $\mathrm{y}=2.6279 \mathrm{x}-0.1794$ \\
CI edge & 800,550 & 0.43 & 1.80 & 35.30 & $\mathrm{y}=0.3486 \mathrm{x}+1.7115$ \\
NDRE & 800,720 & 0.73 & 1.27 & 24.92 & $\mathrm{y}=0.5498 \mathrm{e}^{4.3685 \mathrm{x}}$ \\
\hline
\end{tabular}

Note: The UAV data were obtained in 2015 (data set 12), and the panicle adjustment coefficient ( $\theta$ ) for the PRDVI was 0.13 . 


\section{Discussion}

Vegetation index, which is widely used in inversion of agronomic parameters at various scales, has been continuously improved and developed to obtain higher accuracy of target inversion. Xu et al. [46] devised normalized difference canopy shadow index (NDCSI) to accurately calculate the fractional cover of illuminated/shaded vegetation. Tanaka et al. [47] developed a simple index (DSI R760-R739) for the timely and nondestructive monitoring of LAI. Hallik et al. [48] proposed $R_{751} / R_{736}$ for leaf chlorophyll content estimation, which also performed well at the canopy level. However, previous studies seldom considered the influence of panicles in the late growth stages of rice. The accuracy of VIs is largely influenced by pure vegetation canopy reflectance. However, canopy reflectance is affected by canopy structure and the physiological and biochemical characteristics of the vegetation [49]. In later growth periods of rice, especially after the heading stage, the appearance of panicles has a great effect on canopy structure. As a result, canopy reflectance also changes.

\subsection{Influence of Panicle in Reflectance of Rice Canopy}

Different cultivars with different physiological and structural characteristics caused differences in the morphological characteristics of panicles. Different $N$ treatments applied during the growing periods led to a difference in the number of rice panicles per unit area. These differences determined the extent of the influence of panicles on rice canopy spectra. The results of this study show that rice canopy reflectance considerably changed after the removal of the panicle layer, which is similar to the findings of $\mathrm{Li}$ et al. [26]. Canopy reflectance after the removal of the panicle layer was significantly different from the original reflectance in the 450-1350, 1450-1780, and 1970-2350 nm ranges. The difference before and after panicle removal gradually decreased with decreasing planting density, which led to an increase in the effect of soil and water background, a decrease in the number of rice panicles, and a decrease in the influence of rice panicles on canopy reflectance spectra. Consequently, at the lowest density (D4) that was used in this study, canopy reflectance spectra after panicle layer removal were almost equal to that of the original canopy. At a similar planting density, high $\mathrm{N}$ application resulted in greater reflectance after the removal of the panicle layer when compared with low $\mathrm{N}$ application, which may be the result of more panicles appearing with high $\mathrm{N}$ application [50]. Therefore, more panicles had a greater impact on canopy reflectance.

Tian et al. [51] showed that rice canopy reflectance increased with increasing VC. Therefore, the increase in $\mathrm{N}$ fertilization increased the VC as well as the canopy reflectance. V3 in this study is a japonica rice variety with erect leaves and panicles. The leaves are sparse and they may not completely close with low $\mathrm{N}$ treatment, even after the plants reach maturity (similar $\mathrm{N}$ levels and higher planting density result in lower average $\mathrm{N}$ content per plant). The removal of the panicle layer decreased the VC value, which resulted in an increase in the effect of water and soil background. However, the effect of panicle removal on VC was lower with high $\mathrm{N}$ treatment (similar $\mathrm{N}$ levels and higher planting density result in lower average $\mathrm{N}$ content per plant) because of the dense leaves. Therefore, in the V3 variety, the difference in reflectance in $350-1350 \mathrm{~nm}$ after the removal of panicles gradually decreased with decreasing planting density, and an increase in the $\mathrm{N}$ rate could intensify the reduction. V4 is an indica rice variety with spread leaves and panicles, and its leaves close after heading. Therefore, the variation in planting density had fewer effects on V4 as compared with V3. Different morphological structures of rice panicles had different effects on canopy structure and thus different effects on canopy reflectance [25]. The morphology, color, and reflectance of panicles greatly changed with their maturity, and the difference in reflectance between the panicles and leaves was further magnified. Therefore, there was a change in the red-edge position in the rice canopy spectra before and after panicle removal at the maturing stage (117 DAT). 


\subsection{Influence of Panicles on LAI Estimation Accuracy}

In the present study, the partial VIs that were calculated using canopy reflectance after panicle removal improved LAI estimation accuracy. This indicates that the emergence of panicles is a factor that influences LAI estimation accuracy when using vegetation indices during the late growth stages of rice. The spectral reflectance of pure panicles is typical of vegetation while the spectral reflectance of soil differs from that of vegetation. Therefore, soil background is still the predominant factor affecting canopy reflectance when its effect is large, although the panicles also have an effect on canopy reflectance [49,52,53]. Partial VIs (DI, RDVI, SAVI, OSAVI, TVI, MTVI2, and EVI) exhibited better performance in LAI estimation when using canopy reflectance after panicle removal (data set 6) as compared with using the original canopy reflectance, which suggested that the influence of water and soil background persists in the late growth stage of rice, even in the absence of the effects of the panicle layer. Therefore, the influence of soil and water background should also be considered in the late growth stages of rice.

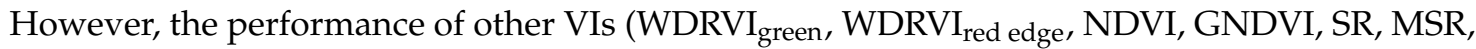
$\mathrm{CI}_{\text {red edge, }} \mathrm{CI}_{\text {green, }}$ and NDRE) in LAI estimation was worse when using canopy reflectance after panicle removal than when using the original canopy reflectance. This may be because the WDRVI green,

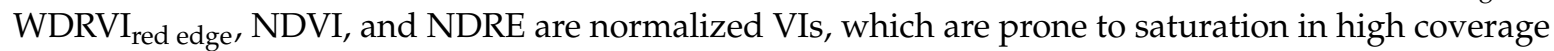
conditions when the LAI value is greater than $3 \mathrm{~m}^{2} / \mathrm{m}^{2}$ [33]. After panicle removal, the leaf area information was dominated by canopy spectra, which exacerbated the saturation effect of the VIs.

$\mathrm{CI}_{\text {red edge }}$ and $\mathrm{CI}_{\text {green, }}$ which are based on the relationship between chlorophyll and LAI, performed well in the estimation of LAI in the early growth stage of rice [54,55]. However, LAI has also been reported to be well correlated with biomass [34,56]. During the late growth stage of rice, a decrease in chlorophyll is usually accompanied by an increase in aboveground biomass and the senescence information of the middle and lower leaf layers is difficult to obtain while using canopy reflectance, which is measured by sensors that are perpendicular to the canopy [26]. Therefore, LAI estimation accuracy decreased when using such chlorophyll-sensitive VIs.

The appearance and growth of fruiting organs such as rice panicles increased the variation rate of reflectance spectra in the near-infrared region as compared with that in the red band because of the high reflectance of the short-wave near-infrared band [4]. The maximum LAI value was attained around the heading stage, and it then gradually decreased [57]. In addition, the visible band that is represented by the red band $(670 \mathrm{~nm})$ was greatly affected by rice panicles in the post-heading stage (Figure 3b). Therefore, during the reproductive growth stage, the performance and accuracy of LAI estimation for some VIs (GNDVI, SR, and MSR) were not as adequate as those in the vegetative growth stage, which is supported by previous studies $[4,58]$.

\subsection{Elimination of the Impact of Panicle and Background}

Previous studies have focused more on the effects of aging and panicles on the canopy structure during the late growth stages of a crop [25,26]; however, this approach ignores background factors, such as soil and water. In the process of developing the PRDVI, we considered various canopy background factors, and the influence of background and panicles on LAI estimation accuracy was weakened in terms of the vegetation index form and spectral band, respectively.

Firstly, the RDVI, which combines the advantages of the NDVI and DI, has been applied to LAI monitoring in different vegetation coverage conditions [14]. Secondly, the red-edge band (720-740 nm), which is one of the most recognizable signs of vegetation spectra, has been increasingly used to replace the red band and construct novel vegetation indices; thus, the red-edge band has been frequently applied to extract LAI from the ground hyperspectral, airborne hyperspectral, and satellite images [34-37,59]. The results of the present study also show that combinations of near-infrared and red-edge bands in any forms of vegetation indices had higher accuracy in estimating LAI than other band combinations, whether in the pre-heading stage or the post-heading stage (Table 5). Moreover, the stable red-edge position of the rice canopy spectra before and after panicle removal (Table 4) also 
indicates that the red-edge band was less affected by rice panicles than the other bands: it was only affected in the ripening stage (117 days after transplanting, the color, shape, and maturity of panicles underwent extensive changes). Similar to our study, some previous studies have reported that VIs using red-edge wavelengths are closely related to the LAI of wheat $[47,60]$ and pasture biomass [61]. Therefore, we replaced the red band in the RDVI with the red-edge band to strengthen the sensitivity to LAI and weaken the influence of panicles. Finally, the rice panicle adjustment factor $(\theta)$ was obtained from the "rice panicle line" to adjust the near-infrared band, which is greatly affected by panicles and coverage; therefore, the effects of background and panicle were further weakened.

Although the PRDVI uses the an average of a wide spectral range, which may result in the loss of key information being available in a particular narrow band, it avoids errors that are caused by a difference of the OBCs of narrow-band VIs with different data sets, and the results of the present study show that LAI estimation accuracies of narrow-band VIs were not higher than those of the broad-band vegetation index PRDVI. Similar results were obtained in previous studies [31,42].

There were some differences in the panicle adjustment factor $(\theta)$ for different panicle types, and the PRDVI could better estimate LAI when $\theta$ was equal to 0.13 . Combining two rice varieties to construct the "rice panicle line" could not completely eliminate the effects of different panicle types (due to different rice types and varieties), especially for high LAI conditions, in which the influence of the panicle layer on canopy reflectance was noticeable, and the effects of different varieties on rice panicle morphology and their distribution in the canopy became more apparent. Therefore, in future studies, we will obtain rice panicle spectra from more rice varieties and use multi-angle spectral information from rice panicles to test and improve the PRDVI.

\section{Conclusions}

In the present study, we investigated the spectral reflectance of panicles and the changes in canopy reflectance after panicle removal. The performance of multiple VIs in LAI estimation was evaluated in both the pre-heading and post-heading stages. We also determined the major factors that influence LAI estimation spectral indices during the post-heading stage. The results demonstrate that rice panicles significantly changed the canopy structure and affected the visible band of canopy spectral reflectance, especially in the red band $(670 \mathrm{~nm})$. However, some red-edge bands $(720-740 \mathrm{~nm})$ were less affected by the panicles. Multiple VI band combinations for LAI estimation reveal that the near-infrared and red-edge band combination was optimal. A "panicle line" was constructed to obtain the panicle adjustment factor by using the near-infrared and red-edge bands. We replaced the red band in the RDVI with the red-edge band, which is less affected by rice panicles, and then introduced the panicle adjustment factor to construct a new type of vegetation index-the PRDVI. The PRDVI significantly minimized the influence of panicles and background on canopy spectra and improved the accuracy of LAI estimation during the post-heading stage. These results fill a gap in the literature and provide a more accurate method for estimating LAI during the post-heading stage.

Author Contributions: Conceptualization, J.H. and Y.T.; methodology, J.H.; investigation, N.Z., X.S. and J.L.; writing-original draft preparation, J.H. and Y.T.; writing—review and editing, Y.T, X.Y., T.C., Y.Z. and W.C.

Funding: This work was supported by the National Key R\&D Program (2018YFD0300805); the Science and Technology Support Program of Jiangsu [BE2016375]; and the Priority Academic Program Development of Jiangsu Higher Education Institutions (PAPD).

Acknowledgments: We would like to thank Yehui Qin, Liyun Zhao, and Xiang Zhou for their help with field data collection. We are grateful to constructive suggestions provided by three anonymous reviewers.

Conflicts of Interest: The authors declare no conflict of interest.

\section{References}

1. Bulcock, H.H.; Jewitt, G.P.W. Improved spatial mapping of leaf area index using hyperspectral remote sensing for hydrological applications with a particular focus on canopy interception. Hydrol. Earth Syst. Sci. Discuss. 2009, 6, 5783-5809. [CrossRef] 
2. Chen, J.M.; Cihlár, J. Retrieving Leaf Area Index of boreal conifer forests using Landsat TM images. Remote Sens. Environ. 1996, 55, 153-162. [CrossRef]

3. Bréda, N.J.J. Ground-based measurements of leaf area index: A review of methods, instruments and current controversies. J. Exp. Bot. 2003, 54, 2403-2417. [CrossRef] [PubMed]

4. Gitelson, A.A.; Peng, Y.; Arkebauer, T.J.; Schepers, J. Relationships between gross primary production, green LAI, and canopy chlorophyll content in maize: Implications for remote sensing of primary production. Remote Sens. Environ. 2014, 144, 65-72. [CrossRef]

5. Yang, J.; He, Y.; Aubrey, D.P.; Zhuang, Q.; Teskey, R.O. Global patterns and predictors of stem $\mathrm{CO}_{2}$ efflux in forest ecosystems. Glob. Chang. Boil. 2016, 22, 1433-1444. [CrossRef] [PubMed]

6. Liu, Y.B.; Xiao, J.F.; Ju, W.M.; Zhu, G.L.; Wu, X.C.; Fan, W.L.; Li, D.Q.; Zhou, Y.L. Satellite-derived LAI products exhibit large discrepancies and can lead to substantial uncertainty in simulated carbon and water fluxes. Remote Sens. Environ. 2018, 206, 174-188. [CrossRef]

7. Delegido, J.; Verrelst, J.; Rivera, J.P.; Ruiz-Verdú, A.; Moreno, J. Brown and green LAI mapping through spectral indices. Int. J. Appl. Earth Obs. Geoinf. 2015, 35, 350-358. [CrossRef]

8. Ren, H.; Zhou, G.; Zhang, F. Using negative soil adjustment factor in soil-adjusted vegetation index (SAVI) for aboveground living biomass estimation in arid grasslands. Remote Sens. Environ. 2018, 209, 439-445. [CrossRef]

9. Feng, W.; Guo, B.B.; Wang, Z.J.; He, L.; Song, X.; Wang, Y.H.; Guo, T.C. Measuring leaf nitrogen concentration in winter wheat using double-peak spectral reflection remote sensing data. Field Crop. Res. 2014, 159, 43-52. [CrossRef]

10. Jordan, C.F. Derivation of Leaf-Area Index from Quality of Light on the Forest Floor. Ecology 1969, 50, 663-666. [CrossRef]

11. Guo, Y.; Zhang, L.; Qin, Y.; Zhu, Y.; Cao, W.; Tian, Y. Exploring the Vertical Distribution of Structural Parameters and Light Radiation in Rice Canopies by the Coupling Model and Remote Sensing. Remote Sens. 2015, 7, 5203-5221. [CrossRef]

12. Li, P.; Wang, Q. Developing and validating novel hyperspectral indices for leaf area index estimation: Effect of canopy vertical heterogeneity. Ecol. Indic. 2013, 32, 123-130. [CrossRef]

13. Baret, F.; Guyot, G. Potentials and limits of vegetation indices for LAI and APAR assessment. Remote Sens. Environ. 1991, 35, 161-173. [CrossRef]

14. Roujean, J.-L.; Bréon, F.-M. Estimating PAR absorbed by vegetation from bidirectional reflectance measurements. Remote Sens. Environ. 1995, 51, 375-384. [CrossRef]

15. Chen, J.M. Evaluation of Vegetation Indices and a Modified Simple Ratio for Boreal Applications. Can. J. Remote Sens. 1996, 22, 229-242. [CrossRef]

16. Huete, A.; Huete, A. A soil-adjusted vegetation index (SAVI). Remote Sens. Environ. 1988, 25, $295-309$. [CrossRef]

17. Rondeaux, G.; Steven, M.; Baret, F. Optimization of soil-adjusted vegetation indices. Remote Sens. Environ. 1996, 55, 95-107. [CrossRef]

18. Kaufman, Y.J.; Tanré, D. Atmospherically Resistant Vegetation Index (ARVI) for EOS-MODIS. IEEE Trans. Geosci. Remote Sens. 1992, 30, 261-270. [CrossRef]

19. Peddle, D.R.; Riddell, K.D.; Hall, F.G. SCAVI: A Sunlit Canopy Adjusted Vegetation Index. Can. J. Remote Sens. 2015, 41, 20-28. [CrossRef]

20. Haboudane, D.; Miller, J.R.; Pattey, E.; Zarco-Tejada, P.J.; Strachan, I.B. Hyperspectral vegetation indices and novel algorithms for predicting green LAI of crop canopies: Modeling and validation in the context of precision agriculture. Remote Sens. Environ. 2004, 90, 337-352. [CrossRef]

21. Kang, Y.; Özdoğan, M.; Zipper, S.C.; Román, M.O.; Walker, J.; Hong, S.Y.; Marshall, M.; Magliulo, V.; Moreno, J.; Alonso, L.; et al. How Universal Is the Relationship between Remotely Sensed Vegetation Indices and Crop Leaf Area Index? A Global Assessment. Remote Sens. 2016, 8, 597. [CrossRef] [PubMed]

22. Jin, X.L.; Diao, W.Y.; Xiao, C.H.; Wang, F.Y.; Chen, B.; Wang, K.R.; Li, S.K. Estimation of Wheat Agronomic Parameters using New Spectral Indices. PLoS ONE 2013, 8, e72736. [CrossRef] [PubMed]

23. Jin, X.L.; Li, Z.H.; Feng, H.K.; Xu, X.G.; Yang, G.J. Newly combined spectral indices to improve estimation of total leaf chlorophyll content in cotton. IEEE J. Sel. Top. Appl. Earth Obs. Remote Sens. 2014, 7, 4589-4600. [CrossRef] 
24. Luo, J.H.; Ma, R.H.; Feng, H.H.; Li, X.C. Estimating the total nitrogen concentration of reed canopy with hyperspectral measurements considering a non-uniform vertical nitrogen distribution. Remote Sens. 2016, 8, 789. [CrossRef]

25. Gutierrez, M.; Reynolds, M.P.; Klatt, A.R. Effect of leaf and spike morphological traits on the relationship between spectral reflectance indices and yield in wheat. Int. J. Remote Sens. 2015, 36, 701-718. [CrossRef]

26. Li, H.L.; Zhao, C.J.; Yang, G.J.; Feng, H.K. Variations in crop variables within wheat canopies and responses of canopy spectral characteristics and derived vegetation indices to different vertical leaf layers and spikes. Remote Sens. Environ. 2015, 169, 358-374. [CrossRef]

27. Zhao, L.; Xu, X.; Zhang, M.; Cheng, T.; Zhu, Y.; Cao, W.; Tian, Y. Development and testing of an ear-leaf model for rice canopy reflectance. J. Appl. Remote Sens. 2018, 12, 016016. [CrossRef]

28. Kawamura, K.; Ikeura, H.; Phongchanmaixay, S.; Khanthavong, P. Canopy Hyperspectral Sensing of Paddy Fields at the Booting Stage and PLS Regression can Assess Grain Yield. Remote Sens. 2018, 10, 1249. [CrossRef]

29. Inoue, Y.; Sakaiya, E.; Wang, C. Potential of X-Band Images from High-Resolution Satellite SAR Sensors to Assess Growth and Yield in Paddy Rice. Remote Sens. 2014, 6, 5995-6019. [CrossRef]

30. Asilo, S.; Nelson, A.; De Bie, K.; Skidmore, A.; Laborte, A.; Maunahan, A.; Quilang, E.J.P. Relating X-band SAR Backscattering to Leaf Area Index of Rice in Different Phenological Phases. Remote Sens. 2019, 11, 1462. [CrossRef]

31. Broge, N.; Mortensen, J. Deriving green crop area index and canopy chlorophyll density of winter wheat from spectral reflectance data. Remote Sens. Environ. 2002, 81, 45-57. [CrossRef]

32. Zhou, X.; Zheng, H.; Xu, X.; He, J.; Ge, X.; Yao, X.; Cheng, T.; Zhu, Y.; Cao, W.; Tian, Y. Predicting grain yield in rice using multi-temporal vegetation indices from UAV-based multispectral and digital imagery. ISPRS J. Photogramm. Remote Sens. 2017, 130, 246-255. [CrossRef]

33. Viña, A.; Gitelson, A.A.; Nguy-Robertson, A.L.; Peng, Y. Comparison of different vegetation indices for the remote assessment of green leaf area index of crops. Remote Sens. Environ. 2011, 115, 3468-3478. [CrossRef]

34. Kross, A.; McNairn, H.; Lapen, D.; Sunohara, M.; Champagne, C. Assessment of RapidEye vegetation indices for estimation of leaf area index and biomass in corn and soybean crops. Int. J. Appl. Earth Obs. Geoinf. 2015, 34, 235-248. [CrossRef]

35. Ali, M.; Montzka, C.; Stadler, A.; Menz, G.; Thonfeld, F.; Vereecken, H. Estimation and Validation of RapidEye-Based Time-Series of Leaf Area Index for Winter Wheat in the Rur Catchment (Germany). Remote Sens. 2015, 7, 2808-2831. [CrossRef]

36. Darvishzadeh, R.; Atzberger, C.; Skidmore, A.; Schlerf, M. Mapping grassland leaf area index with airborne hyperspectral imagery: A comparison study of statistical approaches and inversion of radiative transfer models. ISPRS J. Photogramm. Remote Sens. 2011, 66, 894-906. [CrossRef]

37. $\mathrm{Pu}, \mathrm{R}$.; Cheng, J. Mapping forest leaf area index using reflectance and textural information derived from WorldView-2 imagery in a mixed natural forest area in Florida, US. Int. J. Appl. Earth Obs. Geoinf. 2015, 42, 11-23. [CrossRef]

38. Rouse, J.W.; Haas, R.H.; Deering, D.W.; Schell, J.A.; Harlan, J.C. Monitoring the Vernal Advancement and Retrogradation (Greenwave Effect) of Natural Vegetation. NASA/GSFC Type III Final Report; NASA/GSFC: Greenbelt, MD, USA, 1974.

39. Gitelson, A.A.; Kaufman, Y.J.; Merzlyak, M.N. Use of a green channel in remote sensing of global vegetation from EOS-MODIS. Remote Sens. Environ. 1996, 58, 289-298. [CrossRef]

40. Gitelson, A.A. Wide Dynamic Range Vegetation Index for Remote Quantification of Biophysical Characteristics of Vegetation. J. Plant Physiol. 2004, 161, 165-173. [CrossRef]

41. Peng, Y.; Gitelson, A.A. Application of chlorophyll-related vegetation indices for remote estimation of maize productivity. Agric. For. Meteorol. 2011, 151, 1267-1276. [CrossRef]

42. Broge, N.; Leblanc, E. Comparing prediction power and stability of broadband and hyperspectral vegetation indices for estimation of green leaf area index and canopy chlorophyll density. Remote Sens. Environ. 2001, 76, 156-172. [CrossRef]

43. Huete, A.R.; Didan, K.; Miura, H.; Rodriguez, E.P.; Gao, X.; Ferreira, L.F. Overview of the radiometric and biopyhsical performance of the MODIS vegetation indices. Remote Sens. Environ. 2002, 83, 195-213. [CrossRef]

44. Rundquist, D.C.; Gitelson, A.A.; Viña, A.; Arkebauer, T.J.; Keydan, G.; Leavitt, B. Remote estimation of leaf area index and green leaf biomass in maize canopies. Geophys. Res. Lett. 2003, 30, 52-1-52-4. 
45. Fitzgerald, G.; Rodriguez, D.; O'Leary, G. Measuring and predicting canopy nitrogen nutrition in wheat using a spectral index-The canopy chlorophyll content index (CCCI). Field Crop. Res. 2010, 116, 318-324. [CrossRef]

46. Xu, N.; Tian, J.; Tian, Q.; Xu, K.; Tang, S. Analysis of Vegetation Red Edge with Different Illuminated/Shaded Canopy Proportions and to Construct Normalized Difference Canopy Shadow Index. Remote Sens. 2019, 11, 1192. [CrossRef]

47. Tanaka, S.; Kawamura, K.; Maki, M.; Muramoto, Y.; Yoshida, K.; Akiyama, T. Spectral index of quantifying leaf area index of winter wheat by field hyperspectral measurements: A case study in Gifu Prefectrue, Central Japan. Remote Sens. 2015, 7, 5329-5346. [CrossRef]

48. Hallik, L.; Kuusk, A.; Lang, M.; Kuusk, J. Reflectance Properties of Hemiboreal Mixed Forest Canopies with Focus on Red Edge and Near Infrared Spectral Regions. Remote Sens. 2019, 11, 1717. [CrossRef]

49. Zarco-Tejada, P.J.; Miller, J.; Noland, T.; Mohammed, G.; Sampson, P. Scaling-up and model inversion methods with narrowband optical indices for chlorophyll content estimation in closed forest canopies with hyperspectral data. IEEE Trans. Geosci. Remote Sens. 2001, 39, 1491-1507. [CrossRef]

50. Sui, B.; Feng, X.; Tian, G.; Hu, X.; Shen, Q.; Guo, S. Optimizing nitrogen supply increases rice yield and nitrogen use efficiency by regulating yield formation factors. Field Crop. Res. 2013, 150, 99-107. [CrossRef]

51. Tian, Y.C.; Gu, K.J.; Chu, X.; Yao, X.; Cao, W.X.; Zhu, Y. Comparison of different hyperspectral vegetation indices for canopy leaf nitrogen concentration estimation in rice. Plant Soil 2014, 376, 193-209. [CrossRef]

52. Xiao, Y.F.; Zhao, W.J.; Zhou, D.M.; Gong, H.L. Sensitivity analysis of vegetation reflectance to biochemical and biophysical variables at leaf, canopy, and regional scales. IEEE Trans. Geosci. Remote Sens. 2014, 52, 4014-4024. [CrossRef]

53. Croft, H.; Chen, J.; Zhang, Y. The applicability of empirical vegetation indices for determining leaf chlorophyll content over different leaf and canopy structures. Ecol. Complex. 2014, 17, 119-130. [CrossRef]

54. Boegh, E.; Houborg, R.; Bienkowski, J.; Braban, C.F.; Dalgaard, T.; Van Dijk, N.; Dragosits, U.; Holmes, E.; Magliulo, V.; Schelde, K.; et al. Remote sensing of LAI, chlorophyll and leaf nitrogen pools of crop- and grasslands in five European landscapes. Biogeosciences 2013, 10, 6279-6307. [CrossRef]

55. Nguy-Robertson, A.L.; Peng, Y.; Gitelson, A.A.; Arkebauer, T.J.; Pimstein, A.; Herrmann, I.; Karnieli, A.; Rundquist, D.C.; Bonfil, D.J. Estimating green LAI in four crops: Potential of determining optimal spectral bands for a universal algorithm. Agric. For. Meteorol. 2014, 192, 140-148. [CrossRef]

56. Dong, T.; Liu, J.; Qian, B.; Zhao, T.; Jing, Q.; Geng, X.; Wang, J.; Huffman, T.; Shang, J. Estimating winter wheat biomass by assimilating leaf area index derived from fusion of Landsat-8 and MODIS data. Int. J. Appl. Earth Obs. Geoinf. 2016, 49, 63-74. [CrossRef]

57. Huang, M.; Yang, C.; Ji, Q.; Jiang, L.; Tan, J.; Li, Y. Tillering responses of rice to plant density and nitrogen rate in a subtropical environment of southern China. Field Crop. Res. 2013, 149, 187-192. [CrossRef]

58. Din, M.; Zheng, W.; Rashid, M.; Wang, S.; Shi, Z. Evaluating Hyperspectral Vegetation Indices for Leaf Area Index Estimation of Oryza sativa L. at Diverse Phenological Stages. Front. Plant Sci. 2017, 8, 1-17. [CrossRef]

59. Richter, K.; Hank, T.B.; Vuolo, F.; Mauser, W.; D’Urso, G. Optimal Exploitation of the Sentinel-2 Spectral Capabilities for Crop Leaf Area Index Mapping. Remote Sens. 2012, 4, 561-582. [CrossRef]

60. Li, X.; Zhang, Y.; Bao, Y.; Luo, J.; Jin, X.; Xu, X.; Song, X.; Yang, G. Exploring the Best Hyperspectral Features for LAI Estimation Using Partial Least Squares Regression. Remote Sens. 2014, 6, 6221-6241. [CrossRef]

61. Mutanga, O.; Skidmore, A.K. Narrow band vegetation indices overcome the saturation problem in biomass estimation. Int. J. Remote Sens. 2004, 25, 3999-4014. [CrossRef]

(C) 2019 by the authors. Licensee MDPI, Basel, Switzerland. This article is an open access article distributed under the terms and conditions of the Creative Commons Attribution (CC BY) license (http://creativecommons.org/licenses/by/4.0/). 